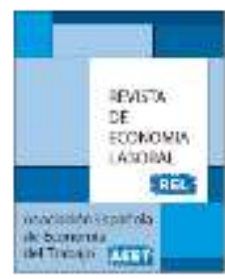

\title{
PROPUESTAS TEÓRICAS Y EVIDENCIA EMPÍRICA SOBRE DESIGUALDAD SALARIAL POR

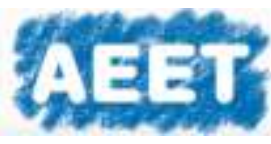 GÉNERO
}

\author{
Reyna Elizabeth Rodríguez Pérez* y Myrna Limas Hernández** \\ *Facultad de Economía de la Universidad Autónoma de Coahuila e **Instituto de Ciencias \\ Sociales y Administración de la Universidad Autónoma de Ciudad Juárez
}

Recibido Diciembre 2017; Aceptado Enero 2018

\section{Resumen}

Las mujeres han aumentado su participación laboral, lo que ha inspirado al planteamiento de algunas teorías y estudios empíricos que estudian los salarios, su determinación y efectos en materia de ocupación, desigualdad por razones de género. El objetivo de esta investigación consiste en hacer una revisión de las teorías y los estudios empíricos que intentan explicar el tratamiento desigual que reciben las mujeres en el mercado laboral. Los principales resultados indican que las mujeres son víctimas de desigualdad en el mercado laboral, aún en el siglo XXI, lo que provoca que sean relegadas en ocupaciones de menor nivel y menos importantes que al ser subvaloradas, esas ocupaciones son consideradas propias o "adecuadas" para ese sexo.

Palabras claves: Economía del género, Diferencias salariales, Mano de obra y empleo Clasificación JEL: J16, J31, J21

(C) Revista de Economía Laboral 


\begin{abstract}
Women have increased their labor participation, which has inspired the approach of some theories and empirical studies that study wages, their determination and effects in terms of occupation, inequality for reasons of gender. The objective of this research is to review the theories and empirical studies that try to explain the unequal treatment women receive in the labor market. The main results indicate that women are victims of inequality in the labor market, even in the XXI century, which causes them to be relegated to lowerlevel occupations and less important than to be undervalued, these occupations are considered proper or "adequate" for that sex.
\end{abstract}

Key Words: Gender Economy, Wage Differences, Labor Force and Employment Classification JEL: J31, J7, B45 


\section{Introducción}

El esfuerzo por resumir en unas cuantas páginas la teoría relacionada con el sistema sexo-género en el mercado laboral es una tarea difícil ante el amplio número de estudios que se han realizado en esta materia. La referencia de partida admite reconocer que el género no es especialmente una categoría que la economía considere prioritaria en su objeto de estudio. Un ejemplo simple es concebir que si revisamos un texto de economía general encontraremos que la teoría microeconómica considera a los agentes económicos como actores clave denominándolos empresas, trabajadores, consumidores, inversores y tomadores de decisiones. Descartando la oportunidad de nombrar a esos agentes como estudiantes que trabajan, trabajadoras domésticas, adolescentes consumidores, empresarios de sexo masculino o femenino, entre otros.

Por ello, resulta importante reconocer la presencia de hombres o mujeres en cada espacio o decisión, que los logros obtenidos por unos y otras en materia de derechos o en su participación creciente en el mercado laboral, en la esfera política y doméstica como en el ejercicio de la maternidad o la paternidad, han inducido a que el estudio de las mujeres en la teoría económica -con las especificidades que ello implicase convierta en una acción más frecuente por parte de diversos(as) estudiosos(as) de esta disciplina.

Por lo anterior, no está de más aclarar que cuando hablamos del sistema sexo-género, teniendo en cuenta a Jacobsen (2004), se alude justo a las diferencias entre hombres y mujeres que pueden deberse a razones biológicas o a las vinculadas con el sexo por un lado y a las construcciones psicológicas, sociales o culturales que se establecen en razón del género. De esta forma, las características sexuales son atributos relacionados con hombres y mujeres en razón de lo biológico y las características del género se asocian con los atributos culturalmente ligados con lo femenino o lo masculino. Y ello supone hacer frente a varias encrucijadas que procede estudiar y descifrar tal como lo sugirieron Benería y Roldán (1992).

Por lo anterior, y al concebir que la diferencia sexual puede implicar desigualdad salarial, en este documento se busca cuestionar: ¿Cuál es la discusión que está detrás de las teorías relacionada con el sistema sexogénero en el mercado laboral? Y en los estudios empíricos que se han elaborado ¿Cuáles son las metodologías, bases de datos, temporalidades y espacios geográficos que se han analizado? 
El objetivo de esta investigación consiste en hacer una revisión de las teorías y los estudios empíricos que intentan explicar el tratamiento desigual que reciben las mujeres en el mercado laboral.

Las teorías sobre desigualdad salarial por género, se analizan desde diferentes posturas como la economía de la familia y la división del trabajo por género; las diferencias salariales por género: el capital humano y la discriminación en el mercado de trabajo; el dualismo y segmentación del trabajo por género; la segregación ocupacional por género; la economía marxista y el género; el género y la economía según las feministas; la crisis económica y el género; las mujeres y la recesión; los estudios económicos con perspectiva de género y, la explotación de las fuentes estadísticas.

$\mathrm{Al}$ revisar los estudios empíricos, se encontró que los resultados varían a través del tiempo, dependiendo del entorno económico, institucional, social y cultural de cada época, pero la mayor parte de ellos, se basan en la teoría económica, específicamente la economía laboral, como el modelo del gusto por la discriminación; la teoría del capital humano; la teoría desde el punto de vista del empresario que desea sacar la máxima rentabilidad de su inversión; teoría de la racionalización de las diferencias a través de la información asimétrica; el locus de control y rendimiento; la autolimitación profesional de las mujeres; el análisis de desigualdad; la brecha salarial explicada por diferencia en la experiencia; el modelo de poder de mercado; la discriminación estadística; los perfiles de ingreso; la segregación jerárquica y ocupacional.

En síntesis estos enfoques teóricos sugieren que las diferencias salariales por género parecen justificarse en la acción de brindar un tratamiento desigual e injusto a las mujeres, donde ellas están obligadas a realizar mayores esfuerzos y hacer frente a más obstáculos para insertarse en el mercado laboral. Por su parte en los estudios empíricos se revela que las féminas sufren desigualdad y discriminación salarial, aún en el siglo XXI, y que ello exige que sean relegadas en ocupaciones de menor calificación o en mercados segmentados, con menores salarios y prestaciones laborales.

El documento se estructura de la siguiente manera: en el primer apartado se discute el sistema sexo-género como factor de diferencias en el mercado laboral. En el segundo y tercero, se revisan algunas propuestas teóricas y estudios empíricos que estudian los salarios, su determinación y efectos en materia de ocupación, desigualdad por razones de género. Finalmente se muestran las conclusiones y la bibliografía utilizada. 


\section{Revisión bibliográfica. El sistema sexo-género como un factor de diferencias en el mercado laboral}

Lamas (1996) considera que el género es un concepto que empezó a ser utilizado en las ciencias sociales en la década de los setenta, como una categoría que hizo posible establecer qué tan variables o universales, son los papeles que marcan la diferente participación de hombres y mujeres en las instituciones sociales, económicas, políticas y religiosas implicando la conceptualización de actitudes, valores y expectativas femeninas o masculinas permitiendo delimitar con claridad y precisión cómo la diferencia cobra la dimensión de desigualdad. Específicamente hace notar que un ambiente que admite ese análisis es justamente el mercado de trabajo.

En el caso de ese mercado, diversas autoras (Jacobsen, 2004; Llorca, 2007; Sánchez y Lavié, 2011; Silva, 2004; De Barbieri, 1991) plantean que los análisis han requerido no solo posicionar la división sexual del trabajo como un eje básico, sino reconocer que hombres y mujeres enfrentan distintos niveles de poder en sus relaciones, por lo que conviene precisar si la subordinación en el ambiente laboral tiende a fortalecerse o a desvanecerse. Entre los pilares de soporte para ese tipo de estudio destacan particularmente los salarios, la presencia o ausencia de remuneraciones, así como sus impactos.

En el caso de los salarios, Fuentes et al. (2005) sugirieron que su determinación dependía de la productividad de cada persona por lo que mayor productividad implicaría percibir un mayor salario. El problema es que no solo no aclararon cómo definir y medir la productividad, sino que en su propuesta consideraban que las mujeres estaban destinadas a ocuparse de los hogares y la maternidad o, en su caso, les correspondía especializarse en un listado finito de actividades laborales remuneradas.

En el caso de los varones, esta propuesta admitía que estaban más y mejor dotados para el mercado laboral, por lo que convenía pagarles mayores salarios a costa de sacrificar o reducir los salarios de las mujeres sin reparo alguno. Así se tiene que estos argumentos promovían diferencias salariales entre hombres y mujeres, al igual que ambientes de discriminación laboral y segregación ocupacional por razones de género.

Pero, a reserva de profundizamos más, en cuestiones de las diferencias salariales, tiene sentido aclarar algunos temas relacionados con la discriminación laboral, su definición y sus particularidades. Fernández (2006) apunta que la discriminación se presenta entre dos 
personas cuando al tener idénticas características y habilidades, y desempeñar las mismas labores, son tratadas de manera diferente por el empleador, sus compañeros o por los consumidores. Y aclara que un mito a romper consiste en precisar si las mujeres ganan menos que los hombres por contar con menores niveles de capital humano, o no, toda vez que es posible encontrar casos donde a igual educación, experiencias y horas trabajadas de mujeres vs hombres, aquellas acceden a menores salarios. Este punto lo veremos más adelante.

Por su parte, Tomei (2006) propone que para entender el significado de discriminación en el mundo del trabajo, el Convenio 111 de la Organización Internacional del Trabajo (OIT) es una fuente acertada. Puntualiza que la discriminación puede ser directa o indirecta. La primera -aclara- refiere a la acción que "incluye normas y reglamentos que excluyen, desfavorecen o manifiestan de manera explícita una preferencia por miembros pertenecientes a determinados grupos sociales (anuncios en el aviso clasificado, vacantes) y, la segunda es "cualquier disposición o práctica, aparentemente imparcial, que redunda en perjuicio de un gran número de integrantes de un determinado colectivo de trabajadores" (empleados en el servicio doméstico sin prestaciones ni regulación).

En síntesis, la autora incentiva a reflexionar sobre el carácter discriminatorio de algunos requisitos mostrados en las especificidades de la demanda de trabajadores (léase estatura, presentación, tez, edad, sexo) radica en su arbitrariedad, ya que no debieran requerirse para el desempeño de los cargos en uno u otro trabajo.

La vinculación entre salarios y discriminación sugiere retomar un apunte de Tenjo et al. (2005) y Fernández (2006) que indica: "no toda la diferencia en salarios es discriminación, ni toda discriminación se traduce en diferencias en salarios [y] las diferencias salariales no son atribuibles exclusivamente a la discriminación de género".

Sobre este punto, Tomei (2006) expone que el nexo entre la discriminación e igualdad de género implica reconocer que la discriminación en el empleo y en la ocupación es un fenómeno cotidiano, universal y cambiante que reviste diversas formas y se manifiesta en todos los entornos laborales.

$\mathrm{Y}$ a ello cabe agregar que, en el caso de la discriminación en contra de las mujeres, Agarwal (1986) apunta que ésta se debe a una variedad de factores históricos, culturales y económicos que, en consonancia con lo apuntado por Tenjo et al. (2005) y Fernández (2006), pueden ocasionar diferencias salariales entre hombres y mujeres, aunque no necesariamente; por lo que la creciente participación de las mujeres en el 
mercado de trabajo ha propiciado reacciones ante el nuevo tipo de mano de obra disponible y requerida.

Por ende, ante las diferencias implícitas auspiciadas en el acceso brindado o no a las mismas oportunidades, el impulso del estudio de las mujeres y del género en la economía se hizo necesario y adquirió fuerza a partir de la década 1960-1970. La pauta que demandó el abordaje de las mujeres en la economía de manera indirecta se atribuye a los esfuerzos realizados por los distintos movimientos de las mujeres (en particular la segunda ola del movimiento feminista) para lograr su emancipación personal, identificar las raíces de la opresión y el trato desigual hacia ellas, como conseguir su incorporación y reconocimiento en el ámbito político, público y económico, dada su presencia o inclusión masiva en el empleo remunerado, sin descuidar actividades no remuneradas.

Por ende, el siguiente apartado expone algunas propuestas teóricas que se han incorporado en la economía, para estudiar el mercado laboral femenino desde la perspectiva de género.

\subsection{Propuestas teóricas del estudio de desigualdades en el mercado laboral desde el enfoque de género}

La presencia creciente de las mujeres en la economía desde 1960 propició focalizar el estudio de los salarios, su determinación y sus efectos en materia de ocupación y discriminación considerando lo apuntado por Mincer (1962), respecto a que las asignaciones de tiempo de las mujeres son diferentes a las de los hombres, ya que ellos por lo regular distribuyen su tiempo entre trabajo remunerado y ocio, pero ellas atienden una opción tridimensional: trabajo de mercado, trabajo doméstico y ocio.

De este modo, la elección de las mujeres para dedicarse de manera exclusiva al hogar o combinar las actividades domésticas no remuneradas con actividades remuneradas, supuso visibilizar algunos vacíos en la teoría económica que procedía incorporar y corregir en los modelos existentes.

En el área de economía laboral observa el estudio de los salarios, ocupaciones y empleos pero no necesariamente aborda la discriminación como un elemento presente en el mercado.

Por ejemplo, las propuestas principales para revisar la determinación de los salarios, el valor (no) asignado al trabajo y sus efectos sobre hombres y mujeres son: i) la Economía de la familia y la división del trabajo por género; ii) las diferencias salariales por género: el capital humano y la discriminación en el mercado de trabajo; iii) el dualismo y segmentación 
del trabajo por género; iv) la segregación ocupacional por género; v) la economía marxista y el género; vi) el género y la economía según las feministas; vii) la crisis económica y el género; viii) Las mujeres y la recesión; ix) los estudios económicos con perspectiva de género $\mathrm{y}, \mathrm{x}$ ) la explotación de las fuentes estadísticas (Castaño, 1999).

Becker (1987, 1976), principal exponente de la economía de la familia y la división del trabajo por género, formuló la teoría general de la asignación del tiempo para cuestionar no solo que hombres y mujeres tenían una carga familiar distinta, donde las decisiones de matrimonio y fertilidad alteraban el enfoque que justificaba que la participación de las mujeres en el mercado de trabajo.

Una prueba de esta adecuación fue que, la incorporación creciente de las mujeres en el mercado de trabajo exigió estudiar las diferencias salariales por género, no solo el salario, con base en la teoría del capital humano, al cuestionarse: ¿Por qué existe una menor ocupación de mujeres en el mercado laboral?, ¿Por qué las mujeres perciben menores salarios que los hombres? Y ¿Por qué motivo las mujeres se concentran en ciertas ocupaciones y sectores económicos?

Por lo que, se procedió a teorizar que cuando se alude, que las características de los trabajos dependen de la productividad de los trabajadores, se establece la teoría de las diferencias igualizantes pero, que en concordancia con Fuentes et al. (2005), existen razones adicionales que dan soporte a la discriminación salarial, en tanto se castiga o premia a un determinado grupo con un menor o un mayor salario. En este recorrido teórico, en el cuadro 1, Fuentes et al. (2005), Marshall (2002), García de Fanelli (1989), entre otras, nos permiten anticipar distintas reflexiones relacionadas con el tema de las desigualdades que viven las mujeres en el mercado laboral. 


\section{Cuadro 1. Propuestas teóricas del estudio de las desigualdades en el mercado laboral con enfoque de género.}

\begin{tabular}{|c|c|c|c|}
\hline Propuesta & Ideas clave & Consideraciones & $\begin{array}{l}\text { Propuestas } \\
\end{array}$ \\
\hline $\begin{array}{l}\text { Fuentes, Palma } \\
\text { y Montero } \\
(2005)\end{array}$ & $\begin{array}{l}\text { Los salarios son un asunto de } \\
\text { señalización, producto del capital } \\
\text { humano y no de la productividad. }\end{array}$ & $\begin{array}{l}\text { A mayor nivel de escolaridad, } \\
\text { mayores capacidades y mayor } \\
\text { salario. }\end{array}$ & $\begin{array}{l}\text { La discriminación salarial } \\
\text { justifica el origen social, la raza, } \\
\text { el idioma u otros componentes } \\
\text { para admitir la magnitud de la } \\
\text { brecha salarial. }\end{array}$ \\
\hline Marshall (2002) & $\begin{array}{l}\text { Las variaciones en el grado de } \\
\text { desigualdad salarial conjugan } \\
\text { varios factores donde las } \\
\text { tendencias del mercado de } \\
\text { trabajo (exceso o escasez de } \\
\text { oferta) constituyen } \\
\text { determinante crucial. }\end{array}$ & $\begin{array}{l}\text { Los factores que intensifican la } \\
\text { desigualdad salarial son el } \\
\text { aumento del desempleo y los } \\
\text { sectores con trabajadores más } \\
\text { fácilmente sustituibles y con } \\
\text { mayor especialización. }\end{array}$ & $\begin{array}{l}\text { Los cambios en la composición de } \\
\text { la demanda en términos de } \\
\text { calificación derivados de la } \\
\text { innovación tecnológica pueden } \\
\text { modificar las brechas salariales } \\
\text { según el nivel educativo y de } \\
\text { calificación de los ocupados. }\end{array}$ \\
\hline Marshall (2002) & $\begin{array}{l}\text { El poder de la intervención } \\
\text { sindical constituye otro factor } \\
\text { que puede contribuir al aumento } \\
\text { o caída de la desigualdad } \\
\text { salarial, al generar una } \\
\text { reducción en la tasa de afiliación } \\
\text { sindical. }\end{array}$ & $\begin{array}{l}\text { El debate no está cerrado dado } \\
\text { que no quedan claros los factores } \\
\text { que generan la desigualdad } \\
\text { salarial. }\end{array}$ & $\begin{array}{l}\text { Recomienda los estudios de } \\
\text { Hanson y Harrison (1999), } \\
\text { Robbins (1994), Galiani y } \\
\text { Sanguinetti (2000), Cristini } \\
\text { (1999), Borland (1996), Leslie y } \\
\text { Pu (1996), Marshall (1999) y } \\
\text { Sylos-Labini (1974) para aceptar } \\
\text { que la desigualdad salarial } \\
\text { puede implicar discriminación } \\
\text { laboral. }\end{array}$ \\
\hline $\begin{array}{l}\text { García de } \\
\text { Fanelli (1989) }\end{array}$ & $\begin{array}{l}\text { Sugiere identificar dos grupos de } \\
\text { conjuntos teóricos de carácter } \\
\text { neoclásico para intentar estudiar } \\
\text { la discriminación. Uno atiende la } \\
\text { perspectiva microeconómica } \\
\text { relacionada con la teoría del } \\
\text { capital humano y el } \\
\text { overcrowding approach (enfoque } \\
\text { de la sobre-agrupación). }\end{array}$ & $\begin{array}{l}\text { En la perspectiva micro, analizar } \\
\text { la conducta de los agentes } \\
\text { económicos y sus motivaciones } \\
\text { reconoce que las diferencias } \\
\text { salariales entre varones y } \\
\text { mujeres, se deben a la menor } \\
\text { productividad de ellas o bien a } \\
\text { las imperfecciones del mercado } \\
\text { (abordadas por el enfoque del } \\
\text { monopsonio), incluidos los } \\
\text { prejuicios. }\end{array}$ & 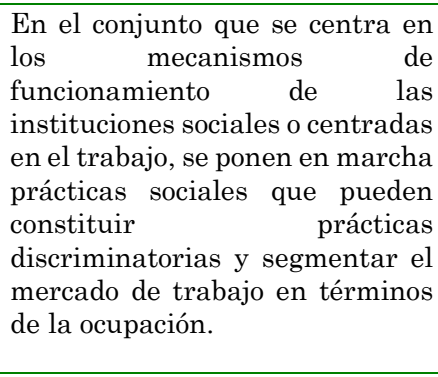 \\
\hline Benería (1983) & $\begin{array}{l}\text { En el proceso centrado en el } \\
\text { trabajo, los enfoques económicos } \\
\text { institucionales permiten } \\
\text { describir dónde están situadas } \\
\text { las mujeres trabajadoras pero no } \\
\text { responden por qué ocurre así. } \\
\text { Considera que existe una } \\
\text { racionalidad económica para } \\
\text { asignar el empleo de la fuerza de } \\
\text { trabajo femenina. }\end{array}$ & $\begin{array}{l}\text { A la fuerza de trabajo femenina } \\
\text { se les asignan algunas } \\
\text { características: el trabajo del } \\
\text { hogar se considera secundario, } \\
\text { poseen una gran destreza } \\
\text { manual, se adaptan a la } \\
\text { realización de tareas repetitivas, } \\
\text { aburridas y que requieren } \\
\text { disciplina y son sumisas y } \\
\text { obedientes. }\end{array}$ & $\begin{array}{l}\text { El problema de segregación y } \\
\text { discriminación ocupacional } \\
\text { responde a factores económicos e } \\
\text { ideológicos que deben vincularse } \\
\text { con la construcción social del } \\
\text { género. }\end{array}$ \\
\hline Benería (1983) & $\begin{array}{l}\text { Reconoce tres fenómenos } \\
\text { asociados con el trabajo } \\
\text { femenino: la segregación por } \\
\text { sexo, la segregación por categoría } \\
\text { y las diferencias en las } \\
\text { remuneraciones. }\end{array}$ & $\begin{array}{l}\text { a) El mercado laboral está } \\
\text { segregado por sexo. Su magnitud } \\
\text { es considerable. b) las mujeres } \\
\text { están segregadas por categoría } \\
\text { ocupacional dentro de cada } \\
\text { ocupación por industria y firma; } \\
\text { y c) existen diferencias } \\
\text { pronunciadas a nivel agregado }\end{array}$ & $\begin{array}{l}\text { Deduce que en la discriminación } \\
\text { salarial y ocupacional se propicia } \\
\text { la concentración de grupos } \\
\text { excluidos (mujeres y minorías) en } \\
\text { los mercados de trabajo internos } \\
\text { y se demanda una alta } \\
\text { estabilidad laboral sin ofrecer a } \\
\text { cambio promociones o carreras }\end{array}$ \\
\hline
\end{tabular}




\begin{tabular}{|c|c|c|c|}
\hline & & $\begin{array}{l}\text { entre las remuneraciones } \\
\text { percibidas por hombres y } \\
\text { mujeres. }\end{array}$ & $\begin{array}{l}\text { de ascenso. Esta dinámica } \\
\text { fomenta la segmentación al igual } \\
\text { que mercados duales donde se } \\
\text { augura que las mujeres han sido } \\
\text { las más perjudicadas. }\end{array}$ \\
\hline $\begin{array}{l}\text { Valdivia } \mathrm{y} \\
\text { Pedrero (2011) }\end{array}$ & $\begin{array}{l}\text { Estudian el enfoque de } \\
\text { segmentación de los mercados } \\
\text { laborales. }\end{array}$ & $\begin{array}{l}\text { Postulan la inexistencia de un } \\
\text { mercado homogéneo que ha dado } \\
\text { cabida a la desigualdad. }\end{array}$ & $\begin{array}{l}\text { La actividad económica genera } \\
\text { segregación en el perfil } \\
\text { demográfico de las personas y } \\
\text { segmentación por la ocupación } \\
\text { que desempeñan en razón de la } \\
\text { desigualdad de ingresos } \\
\text { obtenidos por el trabajo. }\end{array}$ \\
\hline Marshall (2002) & $\begin{array}{l}\text { Al involucrar categorías } \\
\text { ocupacionales, la desigualdad } \\
\text { salarial postula un cambio en la } \\
\text { demanda laboral por trabajo } \\
\text { dado que premia con mayores } \\
\text { salarios a los trabajadores más } \\
\text { calificados. }\end{array}$ & $\begin{array}{l}\text { Los economistas laborales } \\
\text { modernos -a diferencia de } \\
\text { Braverman (1984)- proponen que } \\
\text { el cambio tecnológico demanda } \\
\text { trabajadores más calificados o } \\
\text { con más credenciales. }\end{array}$ & $\begin{array}{l}\text { Los neoclásicos justifican, en } \\
\text { función de un marco de oferta y } \\
\text { demanda laboral, el incremento } \\
\text { de la desigualdad salarial. } \\
\text { La desigualdad salarial se debe } \\
\text { no solo al cambio tecnológico sino } \\
\text { a distintos factores causales (la } \\
\text { liberalización comercial, los } \\
\text { cambios institucionales de las } \\
\text { relaciones laborales, } \\
\text { organización industrial). }\end{array}$ \\
\hline $\begin{array}{l}\text { Organización } \\
\text { Internacional } \\
\text { del Trabajo } \\
\text { (OIT) }\end{array}$ & $\begin{array}{l}\text { Sus propuestas dan soporte a la } \\
\text { concepción dual del mercado } \\
\text { laboral (alta vs baja } \\
\text { productividad, empleos formales } \\
\text { vs informales, empleos decentes } \\
\text { vs precarios, monopolio vs } \\
\text { sectores competitivos). }\end{array}$ & $\begin{array}{l}\text { Los enfoques de la marginalidad, } \\
\text { la concepción "modernista o } \\
\text { desarrollista" y la concepción } \\
\text { "dependentista", la propuesta del } \\
\text { "sector informal" permiten } \\
\text { entender mejor la desigualdad } \\
\text { salarial. }\end{array}$ & $\begin{array}{l}\text { La discusión central es soportar } \\
\text { la hipótesis de que en el mercado } \\
\text { laboral subsiste un sector } \\
\text { primario y otro secundario, un } \\
\text { dualismo, donde operan factores } \\
\text { normativos y de costumbre que } \\
\text { determinan los salarios en lugar } \\
\text { de factores competitivos. }\end{array}$ \\
\hline Castaño (1999) & $\begin{array}{l}\text { Propuesta del mercado dual del } \\
\text { trabajo. }\end{array}$ & $\begin{array}{l}\text { La segmentación del mercado de } \\
\text { trabajo se divide en un mercado } \\
\text { primario y uno secundario. El } \\
\text { primero presenta empleos } \\
\text { estables, bien pagados y con } \\
\text { amplias posibilidades de } \\
\text { promoción profesional. El otro } \\
\text { incluye los empleos inestables, } \\
\text { mal pagados y con escasas o } \\
\text { nulas posibilidades de } \\
\text { promoción. }\end{array}$ & $\begin{array}{l}\text { Las mujeres tienden a ser } \\
\text { excluidas del segmento primario } \\
\text { del mercado de trabajo y } \\
\text { concentradas en el segmento } \\
\text { secundario. De esta manera, } \\
\text { puede identificarse un mercado } \\
\text { segregado por género. }\end{array}$ \\
\hline $\begin{array}{l}\text { Barron y Norris } \\
\text { (1976); Beechey } \\
\text { (1990) }\end{array}$ & Mercado dual del trabajo. & $\begin{array}{l}\text { Barron y Norris (1976) apuntan } \\
\text { que las mujeres trabajadoras se } \\
\text { adecuaban a la descripción de la } \\
\text { mano de obra del mercado } \\
\text { secundario. }\end{array}$ & $\begin{array}{l}\text { Beechey (1990) demuestra en su } \\
\text { estudio la existencia de mujeres } \\
\text { con cualidades típicas del } \\
\text { mercado primario que se } \\
\text { concentraban en profesiones } \\
\text { consideradas típicamente } \\
\text { femeninas (enfermera, maestra). }\end{array}$ \\
\hline $\begin{array}{l}\text { García de } \\
\text { Fanelli (1989) }\end{array}$ & $\begin{array}{l}\text { Reconoce la segregación } \\
\text { ocupacional por género. }\end{array}$ & $\begin{array}{l}\text { El estudio de la participación } \\
\text { femenina en el mercado de } \\
\text { trabajo ha permitido afirmar que } \\
\text { sus credenciales han generado } \\
\text { un crecimiento del sector }\end{array}$ & $\begin{array}{l}\text { En América Latina ha tenido } \\
\text { lugar la concentración de las } \\
\text { trabajadoras en ciertas } \\
\text { ocupaciones } \\
\text { "femeninas" consideradas } \\
\text { telefonista, }\end{array}$ \\
\hline
\end{tabular}




\begin{tabular}{|c|c|c|c|}
\hline & & $\begin{array}{lccc}\text { servicios a } & \text { cambio } & \text { de } \\
\text { remuneraciones. } & & \end{array}$ & $\begin{array}{l}\text { administrativa, secretaria, } \\
\text { mecanógrafa) que se sitúan en un } \\
\text { status menor y con } \\
\text { remuneraciones inferiores en } \\
\text { comparación con las de sus pares } \\
\text { masculinos. Reconoce que la } \\
\text { creación de nuevos patrones de } \\
\text { desigualdad se creó por el género. }\end{array}$ \\
\hline Mann (1986) & Interrupción estudiantil. & $\begin{array}{l}\text { Las mujeres solían interrumpir } \\
\text { sus carreras casi siete años para } \\
\text { dedicarse al cuidado de los hijos } \\
\text { retrasando sus condiciones para } \\
\text { una promoción creando un } \\
\text { reconocimiento desigual en las } \\
\text { trayectorias de hombres y } \\
\text { mujeres. }\end{array}$ & $\begin{array}{l}\text { Las mujeres con niveles de } \\
\text { educación mayores ocuparán los } \\
\text { más bajos escalones del estrato } \\
\text { en consideración, pese a } \\
\text { esforzarse, por razones de } \\
\text { procesos de segregación } \\
\text { ocupacional y de discriminación } \\
\text { salarial por sexo y género. }\end{array}$ \\
\hline $\begin{array}{lr}\text { García } & \text { de } \\
\text { Fanelli } & (1989, \\
1991) & \end{array}$ & $\begin{array}{l}\text { La discriminación contra la } \\
\text { mujer. La literatura sociológica y } \\
\text { económica ha intentado estudiar } \\
\text { este fenómeno. }\end{array}$ & $\begin{array}{l}\text { 1) Se da la segregación } \\
\text { ocupacional en sentido vertical } \\
\text { ya que los puestos de menor nivel } \\
\text { en las escalas jerárquicas de las } \\
\text { distintas empresas son ocupados } \\
\text { por mujeres; 2) La razón de la } \\
\text { segregación ocupacional en } \\
\text { sentido horizontal distingue las } \\
\text { ocupaciones tipificadas como } \\
\text { femeninas o masculinas; y, 3) } \\
\text { Existen diferencias salariales } \\
\text { entre hombres y mujeres. }\end{array}$ & $\begin{array}{l}\text { Se advierte un componente } \\
\text { ausente: el trabajo doméstico. }\end{array}$ \\
\hline $\begin{array}{l}\text { Economía } \\
\text { marxista y el } \\
\text { género } \\
\text { (Marxismo } \\
\text { feminista } \\
\text { Feminismo o } \\
\text { socialista) }\end{array}$ & $\begin{array}{lcr}\text { Exponentes } & 1970 \text { a } & 1990: \\
\text { Hartmann } & (1979, & 1987) \\
\text { Humphries } & (1993), & \text { Rubery } \\
\text { (1993), Beechey (1987), Benería y } \\
\text { Roldán (1992), Rubery (1993) }\end{array}$ & $\begin{array}{l}\text { Las responsables principales del } \\
\text { trabajo doméstico siguen siendo } \\
\text { las mujeres, pese al aumento de } \\
\text { su participación laboral en la } \\
\text { economía. }\end{array}$ & $\begin{array}{l}\text { La división sexual del trabajo es } \\
\text { consecuencia de la explotación de } \\
\text { las mujeres por los hombres en el } \\
\text { seno de la familia. } \\
\text { Consecuencias: a) Ellas ocupen } \\
\text { posiciones subsidiarias en el } \\
\text { mercado de trabajo y, b) La } \\
\text { segmentación de ocupaciones } \\
\text { generan diferencias de ingresos } \\
\text { por género como diferencias en el } \\
\text { acceso a puestos de trabajo. La } \\
\text { desaparición del capitalismo no } \\
\text { garantiza el fin de la opresión de } \\
\text { las mujeres. }\end{array}$ \\
\hline $\begin{array}{l}\text { Economía } \\
\text { feminista } \\
\text { (Auge en la } \\
\text { década } 1980 \text { y } \\
\text { 1990) }\end{array}$ & $\begin{array}{l}\text { La ciencia económica adopta un } \\
\text { carácter "masculinista" o con } \\
\text { sesgo androcéntrico por lo que } \\
\text { asume un carácter universal y } \\
\text { general en los modelos sin } \\
\text { incorporar las condiciones de } \\
\text { género. }\end{array}$ & $\begin{array}{l}\text { Conviene adecuar las } \\
\text { <condiciones imperfectas> como } \\
\text { críticas situando el análisis de } \\
\text { países y mercados por periodos } \\
\text { temporales donde los temas } \\
\text { económicos pierdan } \\
\text { protagonismo en la investigación } \\
\text { feminista y se "humanice" la } \\
\text { teoría. }\end{array}$ & $\begin{array}{l}\text { Recomiendan que las } \\
\text { aproximaciones } \\
\text { multidisciplinares y multi- } \\
\text { metodológicas complementen las } \\
\text { categorías analíticas típicamente } \\
\text { masculinas con otras femeninas } \\
\text { evitando el uso excesivo de } \\
\text { sofisticados } \\
\text { matemáticos para ampliar las } \\
\text { visiones que expliquen con mayor } \\
\text { certeza las causas de la división } \\
\text { del trabajo por género. }\end{array}$ \\
\hline
\end{tabular}




\begin{tabular}{l|l|l|l}
\hline Ion (2011) & $\begin{array}{l}\text { La trayectoria profesional de las } \\
\text { mujeres en el ambiente laboral se } \\
\text { vincula con la existencia de un } \\
\text { techo de cristal. }\end{array}$ & $\begin{array}{l}\text { El techo de cristal puede limitar } \\
\text { la posibilidad del crecimiento } \\
\text { personal y desarrollo profesional } \\
\text { de las mujeres. }\end{array}$ & $\begin{array}{l}\text { Las mujeres han sido } \\
\text { históricamente menos } \\
\text { favorecidas en su inserción en el } \\
\text { sistema educativo y en el } \\
\text { mercado laboral. Se acepta que } \\
\text { pese a que hombres y mujeres } \\
\text { tienden a contar con niveles de } \\
\text { educación superior cada vez más } \\
\text { altos, las desigualdades entre } \\
\text { ambos grupos en la esfera } \\
\text { pública y privada no podrán ser } \\
\text { superadas. }\end{array}$ \\
\hline
\end{tabular}

Fuente: Elaboración propia con base en fuentes citadas

Partiendo del análisis de las propuestas teóricas revisadas, se puede deducir que través del tiempo se han presentado diversas posturas que explican las desigualdades por género, dependiendo del entorno económico, institucional, social y cultural de cada época.

Hartmann (1979, 1987), Humphries (1993), Rubery (1993), Beechey (1987), Benería y Roldán (1992), Barron y Norris (1976); Beechey (1990), Castaño (1999), explican las desigualdades de género en el mercado de trabajo, desde la economía marxista y feminista, así como la sociología del trabajo, donde encuentran que las diferencias entre mujeres y hombres, son consecuencia del cambio en los factores económicos e ideológicos que se vinculan con la construcción social, debido principalmente a una división sexual del trabajo (ocupaciones consideradas "femeninas" y "masculinas") como consecuencia de la explotación de las mujeres por los hombres en el seno de la familia. También, hacen una crítica a la ciencia económica, la cual mencionan, adopta un carácter "masculinista" o con sesgo androcéntrico por lo que asume un carácter universal y general en los modelos sin incorporar las condiciones de género.

García de Fanelli (1989), Marshall (2002), Fuentes et al (2005), desde la teoría económica justifica las diferencias salariales, en función de un marco de oferta (cambios en la Población Económicamente Activa (PEA) e institucionales) y demanda laboral (cambio tecnológico, apertura comercial), donde, la brecha entre los trabajadores tiende a ensancharse, dependiendo de su productividad, derivado del nivel de educación, el entrenamiento en el lugar de trabajo y la experiencia. Y que al analizar la conducta de los agentes económicos y sus motivaciones reconoce que las diferencias salariales por género, se deben a la menor productividad de ellas o bien a las imperfecciones del mercado (abordadas por el enfoque 
del monopsonio), incluidos los prejuicios y el overcrowding approach (enfoque de la sobre-agrupación).

Ion (2011), Valdivia y Pedrero (2011), agregan que la elección ocupacional, puede ser el causante de las diferencias salariales por género, por ejemplo, tener un empleo en el sector privado (formal e informal) o público, también ocuparse en ciertas ramas de actividad económica y profesiones. En este caso las mujeres, suelen elegir el mercado laboral público e informal, por considerarlos más conciliadores con su vida familiar y reconocen que tienden a acumular menos capital humano, dado que ocupan su tiempo en trabajo remunerado y en el cuidado del hogar.

García de Fanelli (1989), también menciona que la segregación es un elemento que explica las diferencias salariales por género, esta se puede dar en sentido vertical y/o horizontal, y se produce cuando los puestos de menor nivel en las escalas jerárquicas de las distintas empresas son ocupados por mujeres o cuando las ocupaciones son tipificadas como femeninas o masculinas. Por su parte, Ion (2011) menciona que la trayectoria profesional de las mujeres en el ambiente laboral se vincula con la existencia de un techo de cristal.

En síntesis, planteamientos teóricos se observa que el género no es especialmente una categoría que la economía considere prioritaria en su objeto de estudio, por tanto existe una crítica, del sesgo androcéntrico de la ciencia económica, ya que las diferencias salariales suelen justificarse por capital humano, productividad, sin reconocer la falta de conciliación hogar y trabajo que tienen las mujeres. Estos resultados, han motivado a realizar trabajos empíricos para conocer, en profundidad y confirmar las ventajas y desventajas que tienen las mujeres que se insertan al mercado laboral. Por lo anterior, se consideró importante contar con una revisión de la literatura empírica reciente, con el objetivo de conocer las metodologías, bases de datos y los principales resultados que han obtenido.

\subsection{Estudios empíricos sobre desigualdad por género en el mercado laboral}

Hecha la revisión de algunas posturas teóricas que se han esgrimido para comprender los problemas que enfrenta la mujer en el mercado laboral, en este apartado se procede a presentar en el cuadro 2 , un análisis de los estudios empíricos realizados a nivel internacional.

En esta revisión se encontró que, no todas las teorías mencionadas en el apartado anterior, se prueban empíricamente, las que si lo hacen se 
basan en la teoría económica, específicamente en la economía laboral, por ejemplo: el modelo del gusto por la discriminación de Becker (1976) y Arrow (1973); la teoría del capital humano de Mincer y Polacheck (1974) de Becker (1976), la teoría desde el punto de vista del empresario que desea sacar la máxima rentabilidad de su inversión Thurow (1975), la teoría de la racionalización de las diferencias a través de la información asimétrica de Lunddberg y Starz (1983); la teoría de la segregación de Blau (1972) y Malkiel (1973); el locus de control y rendimiento de Rotter (1966); la autolimitación profesional de las mujeres de Hakim (1979); el análisis de desigualdad de Jenkins (1994); la brecha salarial explicada por diferencia en la experiencia de O'Neill et al. (1996); las contribuciones del género y raza en la segregación ocupacional de Browne y Misra ( $\mathrm{s} / \mathrm{f})$; los modelos de discriminación en el mercado laboral de Altonji y Black (1999) y Caín (1986); la acumulación del capital humano de García de Fanelli (1989); la hipótesis de segregación de Wainerman (1996); el poder de mercado de Madden (1975); la discriminación estadística de Phelps (1972), la concentración de Bergman (1986); las curvas de discriminación de Del Río, Gradín y Cantó (2004); los perfiles de ingreso de Ben-Porath (1970); el modelo del poder de mercado de Robbins (1994), y la segregación jerárquica de Popli (2013) y la segregación ocupacional Duncan y Duncan (1995).

Las metodologías, bases de datos y la aproximación de variables varían por tipo de estudio. La mayor parte de los trabajos analizan las diferencias y la discriminación salarial por género. El método más utilizado es el propuesto por Oaxaca-Blinder (1973), no obstante, en los últimos tiempos se ha realizado la descomposición de la brecha de salarios con metodologías no paramétricas como en el caso de DiNardo et al. (1996); y paramétricas como sugieren Machado y Mata (2005) y Melly (2005) buscando identificar algunos fenómenos en el comportamiento de las diferencias de ingreso por género a lo largo de la distribución, como pueden ser la presencia "techo de cristal" y/o "piso pegajoso"1, con corrección de sesgo de selección (Heckman 1979). De igual manera se ha indagado sobre los factores que explican los cambios en la parte explicada por los atributos de capital humano en términos de características y los precios Chinhui et al. (1991,1993); el método de matching (emparejamiento) de Ñopo (2011), así como el análisis de desigualdad con

\footnotetext{
1 Por "techo de cristal" se entiendo cuando la brecha salarial por sexo (a favor de los hombres) se incrementa en la parte superior de la distribución, indicando la existencia de un tope o techo de ingresos para las mujeres y por "piso pegajoso" se entiende la presencia de una brecha salarial significativamente alta en la parte inferior de la distribución.
} 
el modelo de regresión switching y la aplicación del índice de Jenkins (1994). Recientemente, se destaca la metodología de Firpo, Lemieux y Fortin (2011), la cual permite desarrollar descomposiciones detalladas y estimar el impacto de los cambios en las dotaciones o los rendimientos de una variable explicativa concreta en los cuantiles de interés de la distribución salarial incondicional. De igual manera, para analizar la segregación ocupacional tanto vertical como horizontal por género, se utiliza el Índice de disimilitud de Duncan y medidas de segregación local.

Las metodologías expuestas se han aplicado en diferentes investigaciones a nivel internacional y nacional, y los resultados varían, dependiendo del objetivo de las mismas. Mandel y Semyonov (2014), mencionan que las expectativas laborales tienen una gran importancia en la explicación en las decisiones de capital humano y determinan en gran parte las brechas salariales por género. Respecto a la jornada laboral, Nopo (2011), revela que las brechas son más altas para las mujeres que trabajan de tiempo parcial, con bajo nivel educativo y se concentran en determinado sector económico. Bernat (2009), encuentra que la desigualdad salarial por género tiene mayor impacto en las mujeres universitarias, en ocupaciones profesionales y técnicas, con más de 7 años de experiencia, en los sectores de servicios y manufactura. Por su parte, Hirsch (2013) Del Rio y Villar (2015) Calónico y Ñopo (2008), argumentan que la eliminación de la segregación ocupacional vertical y horizontal reduce la desigualdad salarial por género. Al analizar las diferencias por sectores, Ullibarri (2003) menciona que la educación tiene una mayor rentabilidad para los hombres en el sector privado y para las mujeres en el sector público, Dueñas, Iglesias y Llorente (2015), argumentan que las féminas consiguen salarios más elevados en el empleo con el uso de las TICS. En términos de los cambios institucionales, Wolszczak-Derlacz (2013), Blau y Kahn (1996) la regulación laboral aumenta las brechas en mano de obra altamente calificada, a favor de los hombres.

$\mathrm{Al}$ descomponer las diferencias salariales en la parte explicada y no explicada por los atributos productivos, Chi et. al (2007); Rodríguez y Castro (2014), Mysíková (2012); García y Morales (2006); Ramos et. al. (2002) Oaxaca (1973); Blinder (1973) Hernández (1995), Elder, Goddeeris y Haider (2010); Torresano (2009); Nopo (2003); Di Pásquele y Atucha (2003); Ng (1992); Di Paola y Berges (1997) revelan que las mujeres han aumentado su participación laboral y accedido a los estudios superiores en forma creciente alcanzando un buen desempeño en su rendimiento académico, sino que en algunas áreas han sobrepasado los porcentajes de egreso masculino; sin embargo, siguen percibiendo salarios inferiores sin 
que se justifique en los atributos de capital humano, como consecuencia de la discriminación salarial por género. Aunque, Chinhui et al. (1993), Dinardo et al. (1996), Fuentes et al. (2005), Domínguez y Brown (2010), Rodríguez (2018) encuentran que la brecha salarial por género ha disminuido en el tiempo, a favor de las mujeres, a consecuencia de una caída del salario real de los hombres (este fenómeno se aprecia para México y otros países).

Así mismo, la mayor parte de la investigaciones expuestas, calculan la desigualdad en la parte media de la distribución de salarios, sin embargo, Del Rio Gradin, Cantó (2011); Del Rio et al. (2008); García, Hernández y López Nicolás (2001); Melly (2005); Machado y Mata (2005); Araújo (2015); Popli (2013) y Rodríguez (2018) encuentra una mayor brecha en la parte baja y alta de la distribución, produciendo el llamado "techo de cristal", indicando la existencia de un tope de ingresos para las mujeres y "piso pegajoso" con una brecha salarial significativamente alta en la parte inferior de la distribución. Por su parte, Enamorado et al. (2009) revela que la brecha de salarios en contra de las mujeres se acentuó en la población más pobre.

Cuadro 2. Estudios empíricos sobre desigualdad salarial por género.

\begin{tabular}{|c|c|c|c|c|c|}
\hline Autores & País & Teoría & $\begin{array}{c}\text { Fuente de } \\
\text { información y } \\
\text { periodo }\end{array}$ & Metodología & Principales Hallazgos \\
\hline $\begin{array}{l}\text { Olivetti } \\
\text { Petrolongo } \\
\text { (2008) }\end{array}$ & $\begin{array}{l}\text { Varios países de la } \\
\text { OCDE }\end{array}$ & Diferencias salariales & $\begin{array}{l}\text { Encuesta de panel } \\
\text { de hogares de la } \\
\text { comunidad Europea } \\
1994-2001\end{array}$ & $\begin{array}{l}\text { Se analizan las } \\
\text { diferencias salariales } \\
\text { con corrección de } \\
\text { sesgo, introduciendo a } \\
\text { los no empleados }\end{array}$ & $\begin{array}{l}\text { La diferencia por } \\
\text { género es más alta en } \\
\text { Estados Unidos y en el } \\
\text { Reino Unido, respecto } \\
\text { a Francia y a Europa } \\
\text { del Sur. }\end{array}$ \\
\hline Ñopo (2011) & Mundial 64 países & $\begin{array}{ll}\text { Capital humano } \\
\text { Becker (1967) }\end{array}$ & $\begin{array}{l}\text { East Asian and } \\
\text { Pacific (EAP), } \\
\text { Europe and Central } \\
\text { Asia (ECA), Middle } \\
\text { East and North } \\
\text { Africa (MENA), } \\
\text { South Asia (SA), } \\
\text { Western Europe and } \\
\text { Sub-Saharan Africa } \\
\text { (SSA). 1991 y 2008 }\end{array}$ & Matching & $\begin{array}{l}\text { Las brechas no } \\
\text { explicadas son más } \\
\text { pronunciadas en los } \\
\text { trabajadores de } \\
\text { tiempo parcial y con } \\
\text { bajo nivel educativo }\end{array}$ \\
\hline $\begin{array}{l}\text { Wolszczak- } \\
\text { Derlacz (2013) }\end{array}$ & 18 países de la OCDE & $\begin{array}{lr}\text { Teoríar de } & \text { la } \\
\text { discriminación } & \text { de } \\
\text { Becker (1971) } & \end{array}$ & $\begin{array}{l}\text { Bases de datos de la } \\
\text { OCDE. 1970-2005. }\end{array}$ & $\begin{array}{lr}\text { Relación entre } & \text { el } \\
\text { coeficiente } & \text { de } \\
\text { discriminación } & \text { e } \\
\text { importaciones } & \text { netas. } \\
\text { Menon y Van Der M. } \\
\text { Rodgers (2009) }\end{array}$ & $\begin{array}{l}\text { Un aumento en la } \\
\text { concentración del } \\
\text { sector aumenta la } \\
\text { brecha salarial. La } \\
\text { regulación } \\
\text { institucional aumenta } \\
\text { las brechas en mano } \\
\text { de obra altamente } \\
\text { calificada. }\end{array}$ \\
\hline
\end{tabular}




\begin{tabular}{|c|c|c|c|c|c|}
\hline $\begin{array}{l}\text { Semykina } \\
\text { Linz (2010) }\end{array}$ & $\begin{array}{l}\text { Russia, Armenia y } \\
\text { Kazakhstan }\end{array}$ & $\begin{array}{l}\text { Locus de Control y } \\
\text { rendimiento por Rotter } \\
\text { (1966) }\end{array}$ & $\begin{array}{l}\text { Bases de datos de } \\
\text { Rusia, Armenia y } \\
\text { Kazakhstan. 2005 }\end{array}$ & $\begin{array}{l}\text { Oaxaca-Blinder (1973) } \\
\text { Neumark }\end{array}$ & $\begin{array}{l}\text { Diferencias en LOC } \\
\text { explican el } 7 \% \text { de la } \\
\text { brecha en Rusia, } 5.5 \% \\
\text { en Armenia y menos } \\
\text { del } 3 \% \text { en Kazakhtan }\end{array}$ \\
\hline $\begin{array}{l}\text { Blau y Kahn } \\
(1996)\end{array}$ & $\begin{array}{lr}\text { Austria, } & \text { Alemania, } \\
\text { Hungría, Suiza, Reino } & \\
\text { Unido, } & \text { Noruega, } \\
\text { Estados } & \text { Unidos, } \\
\text { Suecia, Italia } & \end{array}$ & $\begin{array}{l}\text { Desigualdades } \\
\text { salariales por género y } \\
\text { Capital humano, } \\
\text { Becker (1967) }\end{array}$ & 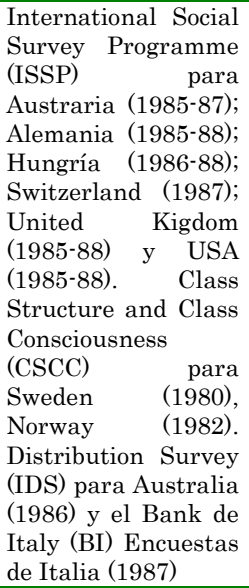 & $\begin{array}{lc}\text { Método } & \text { de } \\
\text { descomposición } & \text { de } \\
\text { diferenciales } & \\
\text { demográficos de Juhn } \\
\text { et al. (1991) }\end{array}$ & $\begin{array}{l}\text { Desigualdad salarial y } \\
\text { descentralización de } \\
\text { fijación de los salarios } \\
\text { generalmente } \\
\text { asociados con las altas } \\
\text { brechas de género }\end{array}$ \\
\hline $\begin{array}{l}\text { Mysíková } \\
(2012)\end{array}$ & $\begin{array}{l}\text { República } \text { Checa, } \\
\text { Hungría, Polonia y } \\
\text { Eslovaquia }\end{array}$ & $\begin{array}{l}\text { Teoría del capital } \\
\text { humano, Becker (1967) } \\
\text { y teoría de la } \\
\text { discriminación, Becker } \\
\text { (1971) }\end{array}$ & $\begin{array}{l}\text { EU-SILC } 2008 \text { para } \\
\text { la República Checa, } \\
\text { Hungría, Polonia y } \\
\text { Eslovaquia. } 2008\end{array}$ & $\begin{array}{l}\text { Oaxaca-Blinder (1973) } \\
\text { y Heckman (1979) }\end{array}$ & $\begin{array}{l}\mathrm{Si} \text { los salarios se } \\
\text { basaran únicamente } \\
\text { en la parte explicada, } \\
\text { las mujeres deberían } \\
\text { de percibir un salario } \\
\text { mayor que los } \\
\text { hombres }\end{array}$ \\
\hline Hirsch (2013) & Alemania & $\begin{array}{l}\text { Desigualdad } \begin{array}{r}\text { salarial } \\
\text { por género, Teoría del } \\
\text { capital } \\
\text { Segregación }\end{array} \\
\text { ocupacional }\end{array}$ & $\begin{array}{l}\text { Employment } \\
\text { Research (LIAB) } \\
2008\end{array}$ & $\begin{array}{l}\text { Efectos fijos de células } \\
\text { de trabajo, para tratar } \\
\text { las segregación } \\
\text { ocupacional }\end{array}$ & $\begin{array}{lr}\text { Constata la } \\
\text { importancia de que las } \\
\text { mujeres se } \\
\text { desempeñen en } \\
\text { puestos de dirección } \\
\text { como medios de } \\
\text { reducción de la } \\
\text { desigualdad salarial }\end{array}$ \\
\hline $\begin{array}{l}\text { García y } \\
\text { Morales (2006) }\end{array}$ & España & $\begin{array}{l}\text { Teoría del Capital } \\
\text { humano, Becker (1967) } \\
\text { y Teoría de la } \\
\text { discriminación } \\
\text { salarial, Becker (1971) }\end{array}$ & $\begin{array}{l}\text { Fichero Técnico de } \\
\text { Afiliados } \\
\text { Empresas } \\
\text { Régimen General de } \\
\text { la Seguridad Social. } \\
\text { 1998-2003 }\end{array}$ & $\begin{array}{l}\text { Técnica de Oaxaca } \\
\text { (1973) y Blinder (1973) }\end{array}$ & $\begin{array}{l}\text { Para España } \\
\text { aproximadamente } \\
83.0 \text { por ciento de las } \\
\text { diferencias salariales } \\
\text { medias, 17.3 puntos } \\
\text { porcentuales, pueden } \\
\text { ser consecuencia de la } \\
\text { discriminación y para } \\
\text { Andalucía los } \\
\text { indicadores son } 72.5 \% \\
\text { de la diferencia } \\
\text { salarial de } 17.7 \text { puntos } \\
\text { porcentuales. }\end{array}$ \\
\hline $\begin{array}{l}\text { Del Rio et al. } \\
(2008)\end{array}$ & España & $\begin{array}{l}\text { Teoría del Capital } \\
\text { humano, Becker (1967) } \\
\text { y Teoría de la } \\
\text { discriminación } \\
\text { salarial, Becker (1971) }\end{array}$ & $\begin{array}{l}\text { Panel de Hogares de } \\
\text { Unión Europea. } \\
\text { (PHOGUE) } 2001 \text { y } \\
\text { OCDE } \\
\text { Employment } \\
\begin{array}{l}\text { Outlook Statical } \\
\text { Annex }\end{array}\end{array}$ & $\begin{array}{l}\text { Jenkins (1994), } \\
\text { discriminación salarial } \\
\text { y deciles de ingreso }\end{array}$ & $\begin{array}{l}\text { Se obtiene una } \\
\text { discriminación del } \\
0.84 \text { en el primer decil } \\
\text { de ingreso y } 0.6 \text { en el } \\
\text { último }\end{array}$ \\
\hline
\end{tabular}




\begin{tabular}{|c|c|c|c|c|c|}
\hline Ullibarri (2003) & España & $\begin{array}{l}\text { Teoría del Capital } \\
\text { humano, Becker (1967) } \\
\text { y Teoría de la } \\
\text { discriminación, } \\
\text { salarial, Becker (1971) }\end{array}$ & $\begin{array}{l}\text { Encuesta } \\
\text { Estructura, de } \\
\text { Conciencia r y } \\
\text { Biografía de Clases } \\
\text { (ECBBC). 1991 }\end{array}$ & $\begin{array}{l}\text { Modelo de regresión } \\
\text { switching y y la } \\
\text { aplicación del índice de } \\
\text { Jenkins (1994) }\end{array}$ & $\begin{array}{l}\text { La educación tiene } \\
\text { una mayor } \\
\text { rentabilidad para los } \\
\text { hombres en el sector } \\
\text { privado y para las } \\
\text { mujeres en el sector } \\
\text { público }\end{array}$ \\
\hline $\begin{array}{l}\text { García, } \\
\text { Hernández y } \\
\text { López Nicolás } \\
(2001)\end{array}$ & España & $\begin{array}{l}\text { Teoría del Capital } \\
\text { humano Becker (1967) } \\
\text { y Teoría de la } \\
\text { discriminación salarial } \\
\text { de Becker (1971) }\end{array}$ & $\begin{array}{lr}\text { Encuesta } & \text { de } \\
\text { Estructura, } & \\
\text { Conciencia } & y \\
\text { Biografía de } & \text { Clase } \\
\text { (1991) } & \end{array}$ & \begin{tabular}{lr}
\multicolumn{2}{l}{ Kuhn: Rendimientos a } \\
características & no \\
observables. & Variable \\
instrumental & para \\
educación &
\end{tabular} & $\begin{array}{l}\text { El piso salarial del } \\
50 \% \text { de los mejores } \\
\text { pagados (hombres) } \\
\text { gana } 12 \% \text { más en } \\
\text { comparación al piso } \\
\text { salarial del } 50 \% \text { de las } \\
\text { mejor pagadas } \\
\text { (mujeres), con un } 90 \% \\
\text { del diferencial no } \\
\text { explicado. }\end{array}$ \\
\hline $\begin{array}{l}\text { Ramos et. al. } \\
(2002)\end{array}$ & España & $\begin{array}{l}\text { El modelo del gusto por } \\
\text { la discriminación de } \\
\text { Becker (1957) y Arrow } \\
\text { (1972); Teoría del } \\
\text { capital humano Mincer } \\
\text { y Polacheck (1974) y } \\
\text { Becker (1975); Teoría } \\
\text { desde el punto de vista } \\
\text { del empresario que } \\
\text { deseara sacar la } \\
\text { máxima de } \\
\text { rentabilidad de su } \\
\text { inversión de Thurow } \\
\text { (1975). Lunddberg y } \\
\text { Starz (1983) } \\
\text { racionalización de las } \\
\text { diferencias a través de } \\
\text { la información } \\
\text { asimétrica. } \\
\text { Segregación de Blau } \\
\text { (1972), Malkiel (1973). }\end{array}$ & $\begin{array}{l}\text { Encuesta elaborada } \\
\text { por los autores. } 2001\end{array}$ & $\begin{array}{l}\text { Ecuación de ingresos } \\
\text { minceriana (1974) }\end{array}$ & $\begin{array}{lr}\text { Las diferencias } \\
\text { salariales no r se } \\
\text { justifican únicamente } \\
\text { por las diferencias en } \\
\text { las características } \\
\text { individuales r y } \\
\text { laborales, sino que } \\
\text { hay evidencia de } \\
\text { discriminación } \\
\text { salarial por razones de } \\
\text { género. }\end{array}$ \\
\hline $\begin{array}{l}\text { Hernández } \\
\text { (1995) }\end{array}$ & España & $\begin{array}{l}\text { Teoría del Capital } \\
\text { Humano Becker (1967) } \\
\text { y discriminación } \\
\text { salarial Becker (1971) }\end{array}$ & $\begin{array}{lr}\text { Encuesta } & \text { sobre } \\
\text { Discriminación } \\
\text { Salarial (EDS) y la } \\
\text { Encuestarr de } \\
\text { Población Activa } \\
\text { (EPA). } 1987\end{array}$ & 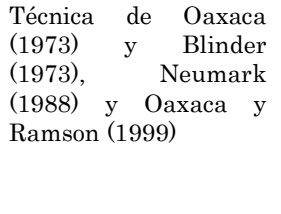 & $\begin{array}{l}\text { Con todas las } \\
\text { metodologías se } \\
\text { prueba que una parte } \\
\text { importante de la la } \\
\text { diferencia salarial se } \\
\text { debe a discriminación } \\
\text { por género. }\end{array}$ \\
\hline $\begin{array}{l}\text { Escot } \\
(2006)\end{array}$ et al. & $\begin{array}{l}\text { Comunidades } \\
\text { Autónomas Españolas }\end{array}$ & $\begin{array}{l}\text { Discriminación en el } \\
\text { mercado laboral de } \\
\text { Becker (1957) y Phelps } \\
(1972) \text { y la } \\
\text { autolimitación } \\
\text { profesional de las } \\
\text { mujeres de Hakim } \\
(2000) \text { r }\end{array}$ & $\begin{array}{l}\text { Panel de Hogares de } \\
\text { Unión Europea. } \\
\text { (PHOGUE) } 2000\end{array}$ & $\begin{array}{lr}\text { Técnica } & \text { de } \\
\text { descomposición } & \\
\text { Oaxaca-Blinder } & \text { con } \\
\text { corrección de sesgo de } \\
\text { selección. Gardeazábal } \\
\text { y Ugidos (2002) para } \\
\text { restricción } \\
\text { identificación. }\end{array}$ & $\begin{array}{l}\text { Se obtiene una medida } \\
\text { de discriminación del } \\
0.52 \text { y una media del } \\
\text { porcentaje en que } \\
\text { debería aumentar los } \\
\text { salarios promedio de } \\
\text { las mujeres en } 15 \% \text {. }\end{array}$ \\
\hline $\begin{array}{l}\text { De la Rica y } \\
\text { Ugidos (1995) }\end{array}$ & España & $\begin{array}{l}\text { Becker y el capital } \\
\text { humano, la teoría de } \\
\text { preferencias y la } \\
\text { discriminación }\end{array}$ & $\begin{array}{lr}\text { Encuesta } & \text { de } \\
\text { Estructura, } & \\
\text { Conciencia } & \mathrm{y} \\
\text { Biografía } & \text { Clase } \\
(1991) & \end{array}$ & $\begin{array}{lr}\text { Técnica } & \text { de } \\
\text { descomposición } & \text { tipo } \\
\text { Oaxaca (1973) }\end{array}$ & $\begin{array}{l}\text { El porcentaje } \\
\text { explicado por las } \\
\text { dotaciones de capital } \\
\text { humano }(14 \%) \text { resulta } \\
\text { ser mucho menor que } \\
\text { el porcentaje no } \\
\text { explicado }(86 \%) \text { que es } \\
\text { el atribuido a la } \\
\text { discriminación. }\end{array}$ \\
\hline
\end{tabular}




\begin{tabular}{|c|c|c|c|c|c|}
\hline $\begin{array}{l}\text { Dueñas, } \\
\text { Iglesias } \quad \text { y } \\
\text { Llorente (2015) }\end{array}$ & España & $\begin{array}{l}\text { Becker y el capital } \\
\text { humano, la teoría de } \\
\text { preferencias y } \text { la } \\
\text { discriminación }\end{array}$ & $\begin{array}{lr}\text { Encuesta } & \text { de } \\
\text { Población } & \text { Activa } \\
(\mathrm{EPA}) 2012 & \end{array}$ & $\begin{array}{l}\text { Ecuaciones salariales y } \\
\text { descomposición } \\
\text { Oaxaca-Blinder }\end{array}$ & $\begin{array}{l}\text { Las mujeres } \\
\text { consiguen salarios } \\
\text { más elevados en el } \\
\text { empleo de TICS. Sin } \\
\text { embargo persiste un } \\
\text { cierto techo de cristal }\end{array}$ \\
\hline $\begin{array}{l}\text { Del Rio Gradin, } \\
\text { Cantó (2011) }\end{array}$ & España & $\begin{array}{lr}\text { Análisis } & \text { de } \\
\text { desigualdad } & \text { de } \\
\text { Jenkins (1994), capital } \\
\text { humano de Becker } \\
\text { (1967), discriminación } \\
\text { salarial de Becker } \\
\text { (1971) }\end{array}$ & $\begin{array}{lr}\text { Encuesta } & \text { de } \\
\text { Población } & \text { Activa } \\
\text { (EPA) 1995 } & \end{array}$ & $\begin{array}{l}\text { Regresión } \\
\text { cuentiles. Juhn et al. } \\
\text { (1991) }\end{array}$ & $\begin{array}{l}\text { Mujeres con salarios } \\
\text { más bajos registran } \\
\text { mayor nivel de } \\
\text { discriminación que los } \\
\text { niveles de salarios } \\
\text { más altos }\end{array}$ \\
\hline Chi et. al (2007) & China & \begin{tabular}{lrr}
\multicolumn{2}{l}{ Desigualdad } & salarial, \\
Teoría del & capital \\
humano de & Becker \\
$(1967)$ & &
\end{tabular} & 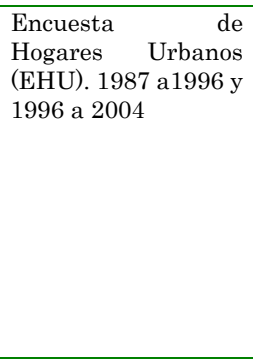 & $\begin{array}{l}\text { Oaxaca-Blinder (1973) } \\
\text { y Firpo-Fortin-Lemiux } \\
\text { (1996) }\end{array}$ & $\begin{array}{lr}\text { En el periodo } \\
\text { analizado se amplió la } \\
\text { brecha salarial por } \\
\text { razones de género } \\
\text { debido a que se } \\
\text { ampliaron } & \text { las } \\
\text { diferencias entre los } \\
\text { individuos } & \text { con } \\
\text { estudios } & \\
\text { universitarios en la } \\
\begin{array}{l}\text { industria y } \\
\text { regiones de china. }\end{array} \\
\end{array}$ \\
\hline Oaxaca (1973) & USA & $\begin{array}{ll}\text { Capital humano } \\
\text { Becker (1967) }\end{array}$ & Censos de 1960 & $\begin{array}{l}\text { Técnica } \text { de } \\
\text { descomposición de la } \\
\text { desigualdad salarial }\end{array}$ & $\begin{array}{lr}\text { Se encontró } & \text { una } \\
\text { concentración } & \text { de } \\
\text { mujeres en trabajos de } \\
\text { bajo salario lo que } \\
\text { impulsa } & \text { la } \\
\text { discriminación } & \text { por } \\
\text { género } & \end{array}$ \\
\hline Blinder (1973) & USA & $\begin{array}{l}\text { Capital humano } \\
\text { Becker (1967) }\end{array}$ & $\begin{array}{lr}\text { Encuestas } & \text { del } \\
\text { Centro } & \text { de } \\
\text { Investigación de } \\
\text { Michigan "Estudio } \\
\text { de panel de la } \\
\text { dinámica de ingreso" } \\
\text { 1968 }\end{array}$ & $\begin{array}{lr}\text { Técnicas } & \text { de } \\
\text { descomposición } & \text { del } \\
\text { diferencial salarial } & \end{array}$ & $\begin{array}{l}2 / 3 \text { de la } \\
\text { discriminación es } \\
\text { directamente de los } \\
\text { mercados de trabajo y } \\
1 / 3 \text { se debe a la } \\
\text { situación laboral y la } \\
\text { antigüedad. }\end{array}$ \\
\hline $\begin{array}{l}\text { Chinhui, } \\
\text { Murphy y Books } \\
\text { (1993) }\end{array}$ & USA & \begin{tabular}{lrr}
\multicolumn{2}{l}{ Desigualdad } & salarial, \\
Teoría & del & capital \\
humano & de & Becker \\
(1967) & &
\end{tabular} & $\begin{array}{l}\text { Current Population } \\
\text { Survey. 1963-1989 }\end{array}$ & $\begin{array}{lr}\text { Técnica } & \text { de } \\
\text { descomposición } & \text { JMP } \\
(1991) & \end{array}$ & $\begin{array}{l}\text { Incremento de la } \\
\text { inequidad de los } \\
\text { hombres de 1963- } \\
\text { 1989. El salario real } \\
\text { de los trabajadores } \\
\text { más educados ha } \\
\text { bajado } 5 \% \text { y el de los } \\
\text { menos educados ha } \\
\text { subido } 40 \% \text {. }\end{array}$ \\
\hline $\begin{array}{l}\text { Dinardo, Fortin } \\
\text { y Lemux (1996) }\end{array}$ & USA & $\begin{array}{l}\text { Teoría del capital } \\
\text { humano Becker (1967) } \\
\text { y teoría de la } \\
\text { discriminación } \\
\text { Becker (1971) }\end{array}$ & $\begin{array}{l}\text { Current Population } \\
\text { Survey. 1979-1988 }\end{array}$ & $\begin{array}{ll}\text { Kernel } & \text { density } \\
\text { estimation } & \end{array}$ & $\begin{array}{l}\text { Los cambios de oferta } \\
\text { y demanda, son } \\
\text { factores importantes } \\
\text { que explican la } \\
\text { desigualdad salarial } \\
\text { de } 1979 \text { a } 1988 \text {. Se } \\
\text { encuentra una caída } \\
\text { en el valor real del } \\
\text { salario mínimo de } \\
1979-1988 \text {, que } \\
\text { explica una parte } \\
\text { importante de la } \\
\text { desigualdad salarial } \\
\text { en la parte inferior de } \\
\text { la curva. }\end{array}$ \\
\hline
\end{tabular}




\begin{tabular}{|c|c|c|c|c|c|}
\hline $\begin{array}{l}\text { Elder, } \\
\text { Goddeeris } \quad y \\
\text { Haider }(2010)\end{array}$ & USA & $\begin{array}{l}\text { Teoría del capital } \\
\text { humano Becker (1967) } \\
\text { y teoría de la } \\
\text { discriminación } \\
\text { Becker (1971) }\end{array}$ & $\begin{array}{l}\text { Current Populación } \\
\text { Survey. 1985-2001 }\end{array}$ & Oaxaca-Blinder (1973) & $\begin{array}{l}\text { Corrigiendo por sesgo } \\
\text { de selección. Se } \\
\text { encontró una brecha } \\
\text { salarial de } 0.28 \text { y una } \\
\text { parte no explicada de } \\
23.3 \%\end{array}$ \\
\hline $\begin{array}{l}\text { Mandel } \\
\text { Semyonov } \\
(2014)\end{array}$ & USA & $\begin{array}{l}\text { O’Neill brecha salarial } \\
\text { se explica por } \\
\text { diferencia en la } \\
\text { experiencia y Blau and } \\
\text { Kahn }\end{array}$ & $\begin{array}{l}\text { Serie de microdatos } \\
\text { de uso público } \\
\text { integrado } \\
\text { (IPUMS)1970-2010 }\end{array}$ & Oaxaca-Blinder & $\begin{array}{l}\text { Las expectativas } \\
\text { laborales tienen una } \\
\text { gran importancia en } \\
\text { la explicación en las } \\
\text { decisiones de capital } \\
\text { humano y explican en } \\
\text { gran parte las brechas } \\
\text { salariales. }\end{array}$ \\
\hline Melly (2005) & USA & $\begin{array}{l}\text { Teoría del capital } \\
\text { humano Becker (1967) } \\
\text { y teoría de la } \\
\text { discriminación } \\
\text { Becker (1971) } \\
\end{array}$ & $\begin{array}{l}\text { Monte-Carlo } \\
\text { simulación }\end{array}$ & $\begin{array}{lr}\text { Estimación } & \\
\text { contrafactual } & \text { usando } \\
\text { regresiones } & \text { por } \\
\text { cuantiles } & \end{array}$ & $\begin{array}{l}\text { Diferencias salariales } \\
\text { entre razas y sexo, y } \\
\text { estas varían a lo largo } \\
\text { de la distribución de } \\
\text { salarios. }\end{array}$ \\
\hline $\begin{array}{l}\text { Machado } \\
\text { Mata (2005) }\end{array}$ & Portugal & \begin{tabular}{lrr}
\multicolumn{2}{l}{ Desigualdad } & salarial, \\
Teoría del & capital \\
humano de & Becker \\
$(1967)$ & &
\end{tabular} & $\begin{array}{ll}\text { Quadros } & \text { Gender } \\
1986-1995 & \end{array}$ & $\begin{array}{l}\text { El método se basa en } \\
\text { distribución de } \\
\text { estimaciones } \\
\text { marginales de salarios } \\
\text { consistentes con una } \\
\text { distracción condicional } \\
\text { estimada por regresión } \\
\text { cuantil }\end{array}$ & $\begin{array}{lr}\text { La } & \text { educación } \\
\text { contribuyó } & \text { a } \\
\text { aumentar } & \text { la } \\
\text { desigualdad } & \text { entre } \\
\text { sexo } & \end{array}$ \\
\hline $\begin{array}{l}\text { Del Rio y Villar } \\
\text { (2015) }\end{array}$ & USA & $\begin{array}{lr}\text { Browne y } & \text { Misra } \\
\text { contribuciones } & \text { del } \\
\text { género y raza en la } \\
\text { segregación } \\
\text { ocupacional }\end{array}$ & $\begin{array}{l}\text { Serie de microdatos } \\
\text { de uso público } \\
\text { integrado } \\
\text { (IPUMS)1980-2012; } \\
\text { Censos } \\
\text { quinquenales } \\
\text { Encuesta } \\
\text { Comunitaria } \\
2000\end{array}$ & $\begin{array}{l}\text { Índice de disimilitud } \\
\text { de Duncan y medidas } \\
\text { de segregación local }\end{array}$ & $\begin{array}{l}\text { Agregando raza/etnia } \\
\text { al estudio de la } \\
\text { segregación por } \\
\text { género demuestra que } \\
\text { esta incremento en } \\
\text { 1/3. Además, en las } \\
\text { mujeres hay una } \\
\text { diferencia marcada } \\
\text { entre asiáticas e } \\
\text { hispanas o latinas. } \\
\text { También las mujeres } \\
\text { están peor posicionas } \\
\text { a comparación de } \\
\text { hombres de la misma } \\
\text { raza }\end{array}$ \\
\hline $\begin{array}{l}\text { Enamorado } \\
\text { al. (2009) }\end{array}$ & $\begin{array}{l}\text { Costa Rica, Honduras, } \\
\text { Nicaragua y el } \\
\text { Salvador }\end{array}$ & $\begin{array}{l}\text { Desigualdades } \\
\text { salariales por género y } \\
\text { Capital humano } \\
\text { Becker (1967) }\end{array}$ & $\begin{array}{lr}\text { Costa } & \text { Rica: } \\
\text { Encuesta de hogares } \\
\text { de } & \text { propósitos } \\
\text { múltiples. } & 1995, \\
2000, & 2006 ; \\
\text { Honduras: } & \text { Encuesta } \\
\text { Permanente } & \text { de } \\
\text { hogares de propósito } \\
\text { múltiples. } & 1997, \\
2002, & 2007 ; \\
\text { Nicaragua: } \\
\text { Encuesta Nacional } \\
\text { de hogares sobre } \\
\text { medición de niveles } \\
\text { de vida. } 1998,2001, \\
\text { 2005; Salvador: } \\
\text { Encuesta de hogares } \\
\text { de } \begin{array}{l}\text { propósitos } \\
\text { múltiples }\end{array}\end{array}$ & Matching & $\begin{array}{l}\text { La parte no explicada } \\
\text { es más pronunciada } \\
\text { entre los individuos } \\
\text { más pobres. Las } \\
\text { mujeres se enfrentan } \\
\text { con barreras a ciertos } \\
\text { perfiles de capital } \\
\text { humano. Las brechas } \\
\text { en Costa Rica }-2.9 \% \text {, } \\
\text { El Salvador } 14.3 \% \text {, } \\
2.6 \% \text { en Nicaragua y } \\
\text { Honduras. } \\
\text { brechas no explicadas } \\
\text { son en Costa Rica } \\
12.2 \% \text {, El Salvador } \\
20.5 \%, \\
12.3 \% \text { yonduras } \\
16.4 \% \text { Nicaragua }\end{array}$ \\
\hline
\end{tabular}




\begin{tabular}{|c|c|c|c|c|c|}
\hline Torresano 2009 & Ecuador & $\begin{array}{l}\text { Modelos } r \\
\text { discriminación en el } \\
\text { mercado laboral de } \\
\text { Altonji y Black (1999), } \\
\text { Caín (1986), Becker } \\
\text { (1957), Blau (2002), } \\
\text { Arow (1973) y Phelps } \\
\text { (1972) }\end{array}$ & $\begin{array}{l}\text { Encuesta de empleo } \\
\text { y desempleo Urbano } \\
\text { y rural (ENEMDUR) } \\
2008\end{array}$ & $\begin{array}{lr}\text { Oaxaca } & (1973) \\
\text { Newmark } & (1988) \\
\text { Heckman } & \text { (1979) }\end{array}$ & $\begin{array}{l}\text { La brecha salarial es } \\
\text { de } 12.36 \% \text { con una } \\
\text { parte no explicada de } \\
18 \% \text {, definida como } \\
\text { discriminación } \\
\text { salarial en contra de } \\
\text { las mujeres }\end{array}$ \\
\hline Ñopo (2003) & Perú & $\begin{array}{lrr}\text { Desigualdad } & \text { salarial, } \\
\text { Teoría del } & \text { capital } \\
\text { humano de } & \text { Becker } \\
\text { (1967) } & & \end{array}$ & $\begin{array}{l}\text { Encuesta Nacionales } \\
\text { de Hogares; } \\
\text { Encuestas } \\
\text { Especializadas de } \\
\text { Empleo; } 1986-2000 .\end{array}$ & Matching & $\begin{array}{l}\text { Se encontró una } \\
\text { brecha salarial de } 46 \% \\
\text { en contra de las } \\
\text { mujeres y la parte } \\
\text { atribuible } \quad \text { a } \\
\text { discriminación en } 28 \%\end{array}$ \\
\hline $\begin{array}{l}\text { Di Pásquele y } \\
\text { Atucha (2003) }\end{array}$ & Argentina & 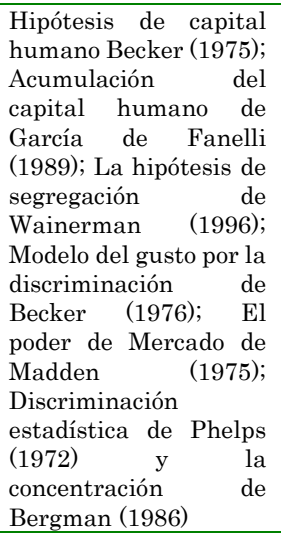 & $\begin{array}{lr}\begin{array}{l}\text { Encuesta } \\
\text { Permanente }\end{array} \\
\text { Hogares } \\
2000 & \text { de } \\
& \end{array}$ & \begin{tabular}{lrrr} 
Método de & \multicolumn{2}{c}{ Oaxaca- } \\
Blinder $\quad(1973) \quad$ y \\
Cotton-Neumark \\
(1988) \\
\end{tabular} & $\begin{array}{l}\text { El } 31.9 \% \text { de la brecha } \\
\text { salarial se explica por } \\
\text { los factores de capital } \\
\text { humano, y el restante } \\
68 \% \text { aparece como el } \\
\text { diferencial } \\
\text { discriminatorio, } \\
\text { siendo } \\
\text { atribuido a } 35.6 \% \\
\text { desventaja femenina y } \\
32.5 \% \text { a la ventaja } \\
\text { masculina. }\end{array}$ \\
\hline $\mathrm{Ng}(1992)$ & Argentina & $\begin{array}{lrr}\text { Desigualdad } & \text { salarial, } \\
\text { Teoría del } & \text { capital } \\
\text { humano de } & \text { Becker } \\
\text { (1967) } & & \end{array}$ & $\begin{array}{lr}\text { Encuesta } & \text { de } \\
\text { Hogares de la ciudad } \\
\text { de Buenos Aires } \\
1985\end{array}$ & $\begin{array}{l}\text { Oaxaca (1973)- } \\
\text { Heckman (1979) }\end{array}$ & $\begin{array}{l}\text { Diferencial salarial de } \\
35 \% \text { del cual no se } \\
\text { explica el } 74 \%\end{array}$ \\
\hline $\begin{array}{l}\text { Di Paola y } \\
\text { Berges (1997) }\end{array}$ & Argentina & $\begin{array}{l}\text { Hipótesis de capital } \\
\text { humano de } \\
(1967) \text {, Hipótesis de } \\
\text { segregación }\end{array}$ & EPH. 1993 y 1997 & $\begin{array}{lll}\begin{array}{l}\text { Oaxaca } \\
(1973)\end{array} & y & \text { Blinder } \\
\end{array}$ & $\begin{array}{l}\text { Las diferencias en las } \\
\text { dotaciones de capital } \\
\text { humano explican un } \\
28 \% \text { y el } 72 \% \text { restante } \\
\text { permanece como } \\
\text { diferencial } \\
\text { discriminatorio. }\end{array}$ \\
\hline Araújo (2015) & Brasil & 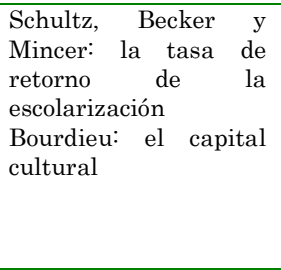 & $\begin{array}{l}\text { Banco de datos del } \\
\text { Instituto del Milenio } \\
\text { (2008) }\end{array}$ & $\begin{array}{l}\text { Regresión cuantílica, } \\
\text { el uso de MCO y } \\
\text { ecuaciones } \\
\text { mincerianas }\end{array}$ & $\begin{array}{l}\text { La desigualdad } \\
\text { salarial de mujeres } \\
\text { respecto a hombres se } \\
\text { ha mantenido casi } \\
\text { igual desde hace } 50 \\
\text { años }(54 \%) \text {. A medida } \\
\text { que aumentan los } \\
\text { percentiles, la brecha } \\
\text { es mayor }\end{array}$ \\
\hline
\end{tabular}




\begin{tabular}{|c|c|c|c|c|c|}
\hline $\begin{array}{l}\text { Fuentes et al. } \\
(2005)\end{array}$ & Chile & $\begin{array}{l}\text { Teoría del capital } \\
\text { humano, Becker (1967) }\end{array}$ & $\begin{array}{l}\text { Encuesta de } \\
\text { caracterización } \\
\text { Socioeconómica } \\
\text { Nacional (CASEN). } \\
1990 \text { y } 2003\end{array}$ & $\begin{array}{l}\text { Oaxaca-Blinder (1973) } \\
\text { y Oaxaca y Ramsom } \\
\text { (1994) }\end{array}$ & $\begin{array}{l}\text { La discriminación } \\
\text { salarial por género ha } \\
\text { disminuido durante } \\
1990 \text { al } 2003 \text {, pero aún } \\
\text { es positiva, situándose } \\
\text { en el } 2003 \text { en } 27.5 \% \\
\text { esto correspondería a } \\
\text { un subgrupo promedio } \\
\text { a las mujeres de } 14.3 \% \\
\text { y un sobrepago } \\
\text { promedio a los } \\
\text { hombres de } 13.2 \% \text {. }\end{array}$ \\
\hline Bernat (2009) & Colombia & $\begin{array}{l}\text { Distribución de } \\
\text { ingresos al análisis de } \\
\text { las diferencias } \\
\text { salariales por género, } \\
\text { hasta la propuesta de } \\
\text { curvas de } \\
\text { discriminación de Del } \\
\text { Rio, Gradín y Cantó } \\
\text { (2004). }\end{array}$ & $\begin{array}{lr}\begin{array}{l}\text { Encuesta } \\
\text { de }\end{array} & \text { Continua } \\
\text { Trimestral. } & \text { (DANE) } \\
2000,2003 \text { y } 2006\end{array}$ & \begin{tabular}{l} 
Oaxaca-Blinder \\
(1973), Heckman \\
\multicolumn{2}{l}{ (1979), Del Rio, Gradín } \\
y Cantó (2004) y \\
Foster, Greer \\
Thorbecke (1984)
\end{tabular} & $\begin{array}{l}\text { Diferencial } \\
\text { explicado en } 2000 \text { es } \\
\text { de } 15.57 \%, 2003 \text { en } \\
22.3 \% \text { y 2006 en } \\
22.73 \% \text {. Con mayor } \\
\text { impacto lo reciben las } \\
\text { mujeres } \\
\text { universitarias, en } \\
\text { ocupaciones } \\
\text { profesionales } \\
\text { técnicas, con más de } 7 \\
\text { años de experiencia, } \\
\text { en los sectores de } \\
\begin{array}{l}\text { servicios } \\
\text { manufactura. }\end{array}\end{array}$ \\
\hline $\begin{array}{l}\text { Mendoza } \\
\text { García (2009) }\end{array}$ & México & $\begin{array}{l}\text { Teoría del capital } \\
\text { humano } \\
\text { Perfiles de ingreso de } \\
\text { Ben-Porath (1970); } \\
\text { Teoría sobre el gusto } \\
\text { por la discriminación } \\
\text { de Becker (1971) }\end{array}$ & $\begin{array}{l}\text { Encuesta Nacional } \\
\text { de Empleo Urbano } \\
\text { (ENOE). } 2006\end{array}$ & $\begin{array}{l}\text { Técnica Oaxaca- } \\
\text { Blinder (1973) }\end{array}$ & 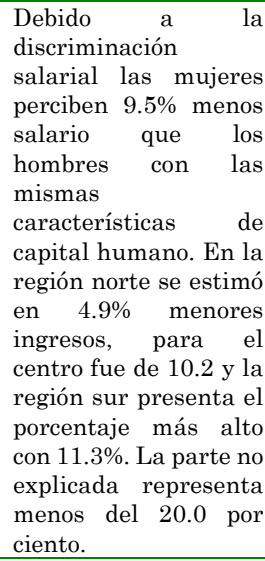 \\
\hline $\begin{array}{l}\text { Rodríguez } \\
\text { Camberos } \\
(2007)\end{array}$ & México & $\begin{array}{lrr}\text { Teoría del capital } \\
\text { humano (1967) y } \\
\text { Teoría sobre la } \\
\text { discriminación salarial } \\
\text { de Becker (1971) }\end{array}$ & $\begin{array}{l}\text { Encuesta Nacional } \\
\text { de Empleo Urbano } \\
\text { (ENEU). } 2001\end{array}$ & $\begin{array}{l}\text { Ecuaciones } \\
\text { mincerianas y técnicas } \\
\text { de descomposición tipo } \\
\text { Oaxaca (1973) }\end{array}$ & 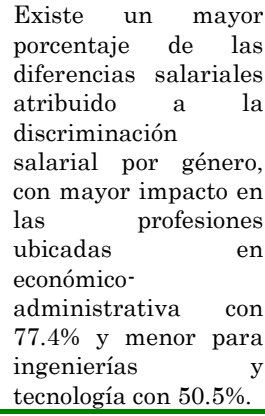 \\
\hline
\end{tabular}




\begin{tabular}{|c|c|c|c|c|c|}
\hline $\begin{array}{l}\text { Martínez y } \\
\text { Acevedo (2004) }\end{array}$ & México & $\begin{array}{l}\text { Teoría sobre } \\
\text { discriminación salarial } \\
\text { y diferencias salariales } \\
\text { con enfoque de género } \\
\text { Becker (1971) }\end{array}$ & $\begin{array}{l}\text { Encuesta Nacional } \\
\text { de Ingreso Gasto de } \\
\text { los Hogares ENIGH } \\
2000\end{array}$ & $\begin{array}{l}\text { Ecuaciones } \\
\text { mincerianas y técnicas } \\
\text { de descomposición tipo } \\
\text { Oaxaca (1973) }\end{array}$ & $\begin{array}{l}\text { Encuentra diferencias } \\
\text { salariales a favor de } \\
\text { los hombres y más del } \\
85.0 \text { por ciento está } \\
\text { asociada } \\
\text { discriminación. con }\end{array}$ \\
\hline $\begin{array}{l}\text { Calónico y Ñopo } \\
\text { (2008) }\end{array}$ & México & $\begin{array}{lr}\text { Teoría del capital } \\
\text { humano, Becker (1967) } \\
\text { y r segregación } \\
\text { ocupacional } & \text { por } \\
\text { género, Duncan } & \text { y } \\
\text { Duncan (1955) } & \end{array}$ & $\begin{array}{l}\text { ENE y ENUE. 1994- } \\
2004\end{array}$ & Matching & 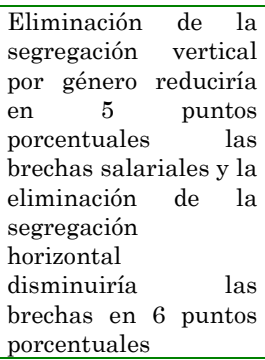 \\
\hline $\begin{array}{l}\text { Sollova- } \\
\text { Manenova y } \\
\text { Salgado-Vega } \\
(2010)\end{array}$ & Estado de México & $\begin{array}{lrr}\text { Parker } & \text { nivel de } \\
\text { ingresos } & \text { depende del } \\
\text { capital humano; y } & \text { humán, Rodríguez, } \\
\text { Rendón, } & \text { diferencia de ingresos } \\
\text { depende de la cultura } \\
\text { social }\end{array}$ & $\begin{array}{l}\text { Censo de Población y } \\
\text { Vivienda } 1990 \quad \text { y } \\
2000\end{array}$ & $\begin{array}{lcc}\text { índice } & \text { Karmel } & \text { y } \\
\text { MacLachlan (1988) } & \end{array}$ & $\begin{array}{l}\text { Las mujeres } \\
\text { continúan ocupándose } \\
\text { en empleos } \\
\text { tradicionales. } \\
\text { Aumento de la } \\
\text { segregación ocupación } \\
\text { ligada a condiciones } \\
\text { económicas poco } \\
\text { favorables }\end{array}$ \\
\hline $\begin{array}{ll}\text { Domínguez } & y \\
\text { Brown (2010) }\end{array}$ & México & $\begin{array}{l}\text { Teoría sobre } \\
\text { discriminación salarial } \\
\text { y diferencias salariales } \\
\text { con enfoque de género } \\
\text { Becker (1971); La } \\
\text { teoríar economía } \\
\text { feminista sobre la no } \\
\text { convergencia de los } \\
\text { salarios en la apertura } \\
\text { comercial de Grown et } \\
\text { al. (2005) }\end{array}$ & $\begin{array}{l}\text { Encuesta Nacional } \\
\text { de Empleo, Salarios } \\
\text { y Capacitación } \\
\text { (ENESTYC) 2001 y } \\
2005\end{array}$ & Modelo de panel & $\begin{array}{l}\text { Efectos negativos de } \\
\text { la orientación hacia la } \\
\text { exportación, tanto en } \\
\text { salario de hombres } \\
\text { como en mujeres. Las } \\
\text { mujeres pierden en } \\
\text { términos absolutos. }\end{array}$ \\
\hline $\begin{array}{l}\text { Arceo y Campos } \\
\text { (2013) }\end{array}$ & México & $\begin{array}{l}\text { Diferencias de retornos } \\
\text { y de dotaciones. } \\
\text { Segregación jerárquica } \\
\text { de Popli }\end{array}$ & $\begin{array}{l}\text { Censos de Población } \\
\text { y Vivienda. } 2010\end{array}$ & $\begin{array}{lr}\text { Método } & \\
\text { semiparamétrico } & \text { con } \\
\text { corrección } & \text { por } \\
\text { selección } & \text { y } \\
\text { descomposición } & \text { por } \\
\text { precios } & \text { y } \\
\text { características DFL } & \end{array}$ & $\begin{array}{l}\text { Brecha salarial se } \\
\text { explica por precios y } \\
\text { no características. } \\
\text { Las mujeres tienen } \\
\text { selección positiva } \\
\text { (mayor para las de } \\
\text { baja educación) }\end{array}$ \\
\hline Popli (2013) & México & $\begin{array}{l}\text { Diferencias de retornos } \\
\text { y de dotaciones. } \\
\text { Segregación jerárquica }\end{array}$ & ENIGH 1996 у 2006 & $\begin{array}{llr}\text { Metodología } & \\
\text { paramétrica y } & \text { no } \\
\text { paramétrica } & \text { con } \\
\text { función de la } \\
\text { expectativa } \\
\text { condicional log-lineal. }\end{array}$ & $\begin{array}{l}\text { La brecha salarial por } \\
\text { género es más alta en } \\
\text { el mercado de mano de } \\
\text { obra formal, aunque } \\
\text { de manera general las } \\
\text { diferencias salariales } \\
\text { han disminuido en el } \\
\text { tiempo (1996-2006) en } \\
\text { ambos mercados, de } \\
\text { igual manera se } \\
\text { encuentra evidencia } \\
\text { de techo de cristal en } \\
\text { el formal, con un } \\
\text { aumento en la parte } \\
\text { no explicada } \\
\text { principalmente en la } \\
\text { cola superior de la } \\
\text { distribución de } \\
\text { ingresos. }\end{array}$ \\
\hline
\end{tabular}




\begin{tabular}{|c|c|c|c|c|c|}
\hline $\begin{array}{l}\text { Rodríguez } \quad y \\
\text { Castro }(2014)\end{array}$ & $\begin{array}{l}\text { Hermosillo y Saltillo, } \\
\text { México }\end{array}$ & $\begin{array}{l}\text { Modelo del poder de } \\
\text { mercado de Robinson, } \\
\text { la teoría del capital } \\
\text { humano de Becker y } \\
\text { Discriminación } \\
\text { estadística de Phelps }\end{array}$ & $\begin{array}{l}\text { Encuesta Nacional } \\
\text { de Ocupación y } \\
\text { Empleo. }\end{array}$ & $\begin{array}{l}\text { Ecuación desarrollada } \\
\text { por Mincer y la } \\
\text { descomposición del } \\
\text { diferencial de salarios } \\
\text { con la técnica de } \\
\text { Oaxaca-Blinder }\end{array}$ & $\begin{array}{l}\text { Discriminación } \\
\text { salarial se mantiene } \\
\text { por niveles educativos } \\
\text { y aumenta con la } \\
\text { edad. En la industria } \\
\text { manufacturera, la } \\
\text { brecha salarial se } \\
\text { asocia con } \\
\text { discriminación. En el } \\
\text { área urbana no hay } \\
\text { grandes diferencias en } \\
\text { la brecha salarial } \\
\text { aunque en Hermosillo } \\
\text { hay mayor nivel de } \\
\text { discriminación } \\
\text { salarial }\end{array}$ \\
\hline $\begin{array}{l}\text { Castro, Huesca } \\
\text { y Otzuca (2015) }\end{array}$ & $\begin{array}{l}\text { Región norte y frontera } \\
\text { de México }\end{array}$ & $\begin{array}{l}\text { Modelo de preferencia } \\
\text { por la discriminación, } \\
\text { Becker, teoria de } \\
\text { capital humano, } \\
\text { Becker y Mincer }\end{array}$ & $\begin{array}{l}\text { Encuesta Nacional } \\
\text { de Ocupación y } \\
\text { Empleo. }\end{array}$ & $\begin{array}{l}\text { Método Oaxaca- } \\
\text { Blinder con corrección } \\
\text { en sesgo de selección } \\
\text { usando Heckman }\end{array}$ & \begin{tabular}{ll}
\multicolumn{3}{l}{ En la frontera norte se } \\
muestra que en la \\
industria, \\
discriminación \\
salarial hacia las \\
mujeres es mayor. \\
Con mayores niveles \\
educativos \\
discriminación \\
disminuye.
\end{tabular} \\
\hline $\begin{array}{l}\text { Orraca, } \\
\text { Cabrera } \\
\text { Iriarte (2016) }\end{array}$ & México & $\begin{array}{l}\text { Teoría del capital } \\
\text { humano (Brown y } \\
\text { Corcoran); } \\
\text { Segregación } \\
\text { ocupacional Duncan y } \\
\text { Duncan (1995) }\end{array}$ & $\begin{array}{l}\text { Censos de Población } \\
\text { y Vivienda. } 2000 \text { y } \\
2010\end{array}$ & $\begin{array}{l}\text { Descomposición } \\
\text { propuesta por Brown }\end{array}$ & $\begin{array}{l}\text { Las diferencias } \\
\text { salariales dentro de } \\
\text { las ocupaciones } \\
\text { tienden a incrementar } \\
\text { la brecha salarial } \\
\text { total, mientras que las } \\
\text { diferencias salariales } \\
\text { entre ocupaciones } \\
\text { presentan el efecto } \\
\text { opuesto. }\end{array}$ \\
\hline
\end{tabular}

Fuente: Elaboración propia con base en la literatura revisada.

Los resultados de las investigaciones varían por temporalidad y unidad geográfica, sin embargo, estos han destacado que los hombres reciben una remuneración mayor que las mujeres, a pesar de que ellas han aumentado sus años educativos y su participación en el mercado de trabajo, así mismo, explican que dichas brechas salariales se deben a factores relacionados con el capital humano, segregación ocupacional, aspectos institucionales (salarios mínimos y sindicatos), mercados segmentados (formal e informal), cambios en la demanda (incorporación de tecnología, apertura comercial y ciclos económicos), y en la oferta (incremento de la mano de obra femenina). Al descomponer dichas diferencias la mayor parte de ellas, no se explican por las características productivas (capital humano), sino por factores inobservables llamados comúnmente discriminación salarial. 


\section{3. ¿De qué manera, a partir de la evidencia empírica, se comprueban las teorías, esbozadas, desde la perspectiva sexo-género?}

Retomando la revisión teórica, y partiendo de que las diferencias entre hombres y mujeres, pueden deberse a razones biológicas y a las construcciones psicológicas, sociales o culturales que se establecen en razón del género, Jacobsen (2004); Llorca, (2007); Sánchez y Lavié, (2011); Silva, (2004); De Barbieri, (1991) plantean que hombres y mujeres enfrentan distintos niveles de poder en sus relaciones, donde la subordinación en el ambiente laboral tiende a traducirse en la división sexual del trabajo. La literatura teórica explica desde diferentes posturas, como la marxista, feminista y la sociología del trabajo principalmente, que la división sexual del trabajo es consecuencia de la explotación de las mujeres por los hombres en el seno de la familia. Consecuencias: a) Ellas ocupen posiciones subsidiarias en el mercado de trabajo y, b) La segmentación de ocupaciones generan diferencias de ingresos por género como en el acceso a mejores puestos de trabajo.

Por su parte los estudios empíricos se basan en la teoría económica, principalmente en la economía laboral, donde las diferencias salariales se explican, en función de un marco de oferta y demanda laboral, donde se incluyen hipótesis de a) Cambio tecnológico, b) Capital humano, c) Liberalización comercial, d) Regulaciones institucionales, y e) segregación ocupacional y sectorial.

Los enfoques teóricos sugieren que las diferencias salariales por género parecen justificarse en la acción de brindar un tratamiento desigual e injusto a las mujeres, donde ellas están obligadas a realizar mayores esfuerzos y hacer frente a más obstáculos (vinculados con compromisos familiares) para insertarse en el mercado laboral. Aunque, no todas las teorías revisadas se prueban en los estudios empíricos, ya que estos se basan en la teoría económica, donde el mercado se rige a través de la oferta y la demanda laboral y las diferencias se justifican por el capital humano y la productividad, sin tomar en cuenta las diferencias de género, en los estudios empíricos se encontró que las féminas sufren desigualdad y discriminación salarial, por décadas y en la actualidad, lo que ha provocado que sean relegadas en ocupaciones de menor calificación o en mercados segmentados, con menores salarios y prestaciones laborales. 


\section{Conclusiones}

El estudio del mercado laboral por economistas y otros científicos sociales ha requerido destacar que en las sociedades se ha establecido una división "natural" del trabajo por sexo donde algunas tareas son consideradas femeninas o masculinas que están supeditadas al cumplimiento de roles de género que, al final, propician relaciones de poder desiguales entre las personas, léase entre hombres y mujeres.

El objetivo de esta investigación consiste en hacer una revisión de las teorías y los estudios empíricos que intentan explicar el tratamiento desigual que reciben las mujeres en el mercado laboral.

En suma, el balance general de la revisión teórica y empírica elaborada, permiten explicar los efectos de la incorporación de la mujer al mercado de trabajo, y sugieren que: i) las mujeres parecen estar obligadas a realizar mayores esfuerzos y hacer frente a más obstáculos para insertarse en el mercado laboral; ii) las diferencias salariales por género parecen justificarse en brindar un tratamiento desigual e injusto a las personas, donde las mujeres se vinculan más con la familia, una vida laboral más corta y discontinua y los hombres se asocian con remuneraciones, poder y jerarquía; iii) la responsabilidad asumida por las mujeres en la esfera doméstica implica que vean reducidos sus ingresos laborales generándose segregación ocupacional; iv) la vulnerabilidad de las mujeres en el mercado laboral como víctimas de discriminación las expone a ser relegadas en ocupaciones menos importantes y subvaloradas que son consideradas "adecuadas" para ellas; v) algunas ocupaciones "reservadas" para los colectivos femeninos pueden estar supeditadas a prejuicios personales, gustos o aspectos raciales vinculados con las conductas de quienes las emplean o cualifican impidiendo su superación y, vi) no existe suficiente argumentación para justificar prácticas de discriminación o de desigualdad en menoscabo de las mujeres.

Por tanto, la preocupación de las mujeres por invertir en su capital humano y conseguir su incorporación plena en la vida pública y al empleo remunerado ha estimulado incorporar en la comprensión de los modelos del pensamiento económico la perspectiva de género, obligando a integrar bases de datos que permitan poner al descubierto las situaciones de desigualdad o discriminación que enfrentan hombres y mujeres en distintos ámbitos sociales y económicos.

En definitiva, la revisión de cómo se manifiesta el acceso a oportunidades entre hombres y mujeres en el plano educativo y la esfera laboral implica su documentación para ser capaces de sugerir estrategias 
en contra de la desigualdad salarial. En este caso, las políticas estimuladoras a favor de la igualdad de trato y de oportunidades habrán de reconocer que una sociedad desigual tiende a repetir la desigualdad en todas sus instituciones de modo que conviene modificar las estigmatizaciones presentes en el análisis de las diferencias entre hombres y mujeres en función de reconocer la divergencia en capacidades pero convergencia en sus salarios.

\section{Bibliografía}

Agarwal, B. (1986). Women, Poverty and Agricultural Growth in India, Journal of Peasant Studies, Vol. 13, No. 4. July. pp.165-220.

Altonji Joseph G. y Black Rebecca M. (1999) Race and Gender in the Labor Market. Institute for Policy Research and Department of Economics, Northwestern University Illinois, United States.

Arceo Eva y Campos Raymundo (2014), “Evolución de la brecha salarial de género en México” El Trimestre Económico, Núm. 323, pp. 619-653.

Arrow, K. (1973). The Theory of Discrimination, on Ashenfelter O. \& Rees, A. Discrimination in Labor Markets. Princeton University Press.

Barron, R. y Norris, G. (1976). Sexual Divisions and the Dual Labour Market en Barker, D. y Allen, S. Dependence and Explotation in Work and Marriage, .Longman, Londres UK.

Becker G. and Nigel Toms $(1967,1975)$ An Equilibrium Theory of the Distribution of Income and Intergenerational Mobility. The Journal of Political Economy, Vol. 87, No. 6, pages 1153-1189. The University of Chicago Press.

Becker G. (1971 y 1957), The Economic of Discrimination. Second Edition. The University of Chicago Press. Pp.167.

Becker, G. (1976). The Economic Approach to Human Behavior. Chicago and London. The University of Chicago Press.

Becker, G. (1987). Tratado sobre la familia, Madrid, Alianza Universidad.

Beechey, V. (1987). The Sexual Division of Labour and the Labour Process: A Critical Assessment of Braverman, Unequal Work. Verso. The Imprint of New Left Books.

Beechey, V. (1990). Género y trabajo. Replanteamiento de la definición de trabajo en Borderías, C., Carrasco, C. y Alemany, C. (1994): Las mujeres y el trabajo. Rupturas conceptuales. MadridBarcelona, Icaria-Fuhem.

Benería, L. (1983). Overcoming Dualisms: Gender, Jobs and Skills. Sociology Department, Liverpool University (mimeo).

Benería, L. y Roldán, M. (1992). Las encrucijadas de clase y género. Fondo de Cultura Económica. Mexico. 
Ben-Porath (1970). The production of human capital and the life-cycle of earnings. The Journal of Political Economy, 75(4):352-365, August 1967. Part 1.

Bergman (1986) Theories of Gender Equality: Lessons from the Israeli Kibbutz. GENDER \& SOCIETY, Vol. 3 No. 2, June 1986, pages 160-186. Herzlia, Israel.

Blau, Francine D. (1972, 2002) “Trends in the Well-being of American Women, 1970-1995," Journal of Economic Literature: Pp.112-165.

Blau, Francine and Lawrence M. Kahn. 1996. Wage structure and gender earnings differentials: An internationals comparison. Economics 63. No. 250: 29-62.

Blinder A. (1973). "Wage discrimination: reduced forms and structural estimates". Journal of Human Resourses, 8(4). The University of Texas at Austin. Pp. 436-455.

Borland, Jeff (1996). Union effects on earnings dispersion in Australia, 1986-1994), British Journal of Industrial Relations, Vol. 34, Núm. 2.

Braverman, H. (1984). Trabajo y capital monopolista. Ed. Nuestro Tiempo. México.

Brown y Corcoran (1997) "Sex-Based Differences in School Content and the Male/Female Wage Gap." Journal of Labor Economics. 15:3, pp. 431-65.

Browne, Irene, and Joya Misra. 2003. "The Intersection of Gender and Race in the Labor Market." Annual Review of Sociology 29: 487-513.

Calónico S. y Ñopo H. (2008). "Gender segregation in the workplace and wage gaps: Evidence from urban México 1994-2004”. In J. Bishop (ed). Ocupational and Residential segregation (Research on Economic Inequality). Vol. 17. Emerald Group Publishing limited.

Castaño, C., Iglesias, C., Manas, E. y Sánchez-Herrero, M. (1999). Diferencia o discriminación. La situación de las mujeres españolas en el mercado de trabajo y el impacto de las tecnologías de la información. Madrid: Consejo Económico y Social.

Castro D., Huesca L. y Zamarrón N. (2015). "Discriminación salarial por género, en la industria manufacturera de la frontera norte de México, en el periodo 2005-2011", Nóesis. Revista de Ciencias Sociales y Humanidades, vol. 24, núm. 47, enero-junio, pp. 50-80 Instituto de Ciencias Sociales y Administración Ciudad Juárez, México.

Chi, Wei; Li, Bo and Yu, Qiumei. (2007). Decomposition of change in earnings inequality in China: A distributional approach. School of economics and management, Tsinghua University. Paper No. 3806: 1-34.

Cotton, J., 1988, "On the Decomposition of the Wage Differentials", The Review of Economics and Statistics, 70(2), 236-243.

Cristini, Marcela (1999). Apertura económica, política comercial y la distribución del ingreso: ¿Qué aporta el caso argentino al debate?, La distribución del ingeso en la Argentina, Buenos Aires. FIEL.

De Barbieri, M. (1991). Los ámbitos de acción de las mujeres, Revista Mexicana de Sociología. Vol. 53, No. 1. Enero-marzo. pp. 203-224.

De Barbieri, T. (2004). Más de tres décadas de los estudios de género en América Latina, Revista Mexicana de Sociología. Vol. 66, Número especial. Octubre. pp. 197-214. 
De la Rica, S y Ugidos, A (1995). ¿Son las diferencias en capital humano determinantes de las diferencias salariales observadas entre hombres y mujeres?. Investigaciones Economicas. Universidad del País Vasco. Vol. 19(3):395-414.

Del Río y Villar (2015) "Mapping the occupational segregaton of white women in the US: Differences across metropolitan areas". Society for the Study of Economic Inequality. Working Paper 352. Universidad de Vigo, España.

Del Río, Carlos y Olga Cantó. 2008. Pobreza y Discriminación Salarial Por Razón De Género en España. Hacienda Pública Española / Revista de Economía Pública. 184 (1): 67-98.

Del Río, Gradín y Cantó (2015). Segregation and Social Welfare. Society for the Study of Economic Inequality. Working Papers 378.

Del Río, Gradín y Cantó (2004). Enfoque Distributivo en el análisis de la discriminación salarial por razón de género. Departamento de Economía Aplicada. Universidad de Vigo, España.

DiNardo, Fortin y Lemieux (1996). "Labor market institutions and the distribution of wages, 19731992: A Semiparametric Approach”. Econometrica. 64(5): 1001-1044, pp. 1001-1044.

Domínguez y Brown (2010). "Determinant of wage differentials in the maquila industry in México: a gender perspective", Working paper num. 07-6. The international working group on gendermacroieconomic-international Economic, salt Lake City, pp.1-24. Economics, 12(4): 577-590.

Dueñas, Diego, Iglesias, Carlos y Llorente, Raquel. 2015. Abordando la desigualdad de género. Empleo en técnicas de información y la comunicación y diferencias salariales por género en España. Ensayos sobre política económica. 33: 207-2019.

Duncan y Duncan (1995). A Methodological Analysis of Segregation Indexes. American Sociological Review 20, April 1955, pp. 210-217.

Elder, Goddeeris y Haider (2010) Unexplained Gaps and Oaxaca Blinder Descompositions. Labour Economics, Elsevier, Vol.17, pages 284-290.

Enamorado, Ted, Ana Carolina Izaguirre, and Hugo Nopo. 2009. Gender Wage Gaps in Central American Countries: Evidence from a Non-Parametric Approach. Inter-American Development Bank. Working Papers Series No. 111: 1-32.

Scott et al (2006) Measuring Gender Equality. Department of Sociology, University of Cambridge.

Fernández, María (2006). Determinantes del diferencial salarial por género en Colombia, 1997-2003, Desarrollo y Sociedad. Núm. 58, Septiembre. Universidad de los Andes.

Firpo S., Fortin N. and Lemieux T. (1996) Unconditional Quantile Regressions, Econometric, vol. 77, No. 3, pp. 953-973.

Foster, Greer y Thorbecke (1984). The Institutional Basis of Gender Inequality: The Social Institutions and Gender Index. International Journal of Humanities and Social Sciences. Vol.5, No.2 pp101-107.

Fuentes, J., A. Palma y R. Montero (2005). Discriminación salarial por género en Chile: una mirada global, Estudios de Economía. Vol. 32. No. 2. Diciembre. pp. 133-157.

Galiani, S. y Sanguinetti, P. (2000). Wage inequality and trade liberalization: evidence from Argentina. Buenos Aires. Mimeo. 
García de Fanelli, A. (1989). Patrones de desigualdad social en la sociedad moderna: una revisión de la discriminación ocupacional y salarial por género, Desarrollo Económico. Instituto de Desarrollo Económico y Social. Vol. 29, No. 114, Julio-septiembre. pp. 239-264.

García de Fanelli, A. (1991). Empleo femenino en la Argentina: de la modernización de los ‘60 a la crisis de los '80, Desarrollo económico. Vol. 31, No. 123, Octubre-diciembre. pp. 395-414.

García, José Ignacio y Morales, María Dolores (2006). Discriminación salarial en el mercado de trabajo español con especial referencia al caso de Andalucía. Centro de estudios Andaluces. Documento de trabajo serie de economía: 1-36.

García Jaume, Hernández Pedro y López Nicolás (2001). How wide is the gap? An investigation of gender wage differences using quantile regression. Empirical economic. 26: 149-167.

Gardeazabal J. and A. Ugidos (2002). Gender Wage Discrimination at quantiles. University of the Basque Country. Journal of Population Economics. Vol.18 pp.165-179.

Grown et al (2005) The Roots of Gender Inequality in Developing Countries. Northwestern University

Hakim (2000) Sex-Differences in Job-Allocation. Work-Lifestyle Choices in the 21st Century: Preference Theory. Oxford University Press.

Hakim, C. (1979). Ocupational Segregation, Research Paper no. 9, Londres, Department of Employment.

Hanson, G. y Harrison, A. (1999).Trade liberalization and wage inequality in Mexico, Industrial and Labor Relations Review, Vol. 52, No. 2.

Hartmann, H. (1979). The unhappy marriage of Marxism and Feminism: Towards a more progressive union. Capital and Class.

Hartmann, H. (1987). Internal Labor Markets and Gender: a Case Study of Promotion en Brown, C. y Pechman, J. (eds.): Gender in the Workplace. Washington, The Brooking Institute.

Hirsch, Boris. 2013. The Impact of Female Managers on the Gender Pay Gap: Evidence from Linked Employer-Employee Data for Germany. Economics Letters. 119(3): 348-350.

Humphries, J. (1993). El empleo de las mujeres en la reestructuración de América en Rubery, J. (1993). Las mujeres y la recesión. Madrid, Ministerio de Trabajo y Seguridad Social.

Jacobsen, J. (2004). The Economics of Gender. Second edition. Blackwell Publishing. United Kingdom.

Jenkins (1994) On Gender Inequality and Life Satisfaction: Does Discrimination Matter? Department of Economics, University of St. Gallen.

Juhn, C., Murphy K. y Pierce B. (1991). "Accounting for the Slowdown in Black-White Convergence”, en M. Osters (ed.) Workers and Their Wages, ed. American Enterprise Institute Press.

Juhn, C., Murphy K. y Pierce B. (1993). "Wage inequality and the rise in returns to skill”. Journal of Political Economy, 101 (31), pp. 410-442. 
Karmel y McLachalan (1988) Occupational Sex Segregation: Increasing or Decreasing? Pages 187195. Volume

Lamas, M. (1996). La perspectiva de género, Revista de Educación y Cultura de la sección 47 del SNTE. Recuperado de Cátedra Derechos Humanos de la UNESCO.

Llorca, M. (2007). Flexibilidad y rigidez en los roles de género en Vega, A. (coord.). Mujer y educación. Una perspectiva de género. Ediciones Aljibe. Málaga.

Machado, Jose and Jose Mata. 2005. Counterfactual decomposition of changes in wage distributions using quantile regression. Journal of Applied Econometrics. 20: 445-65.

Madden, Y. (1975): Discrimination-A Manifestation of Male Market Power en Lloyd, C. (ed.) (1975): Sex, Discrimination and the Division of Labor. New York, Columbia University Press.

Malkiel, Burton G. and Judith A. Malkiel. (1973). "Male-Female Pay Differentials in Professional Employment.” American Economic Review, 63. Pp693-705.

Mandel y Semyonov (2014) Gender Pay Gap and Employment Sector: Sources of Earnings Disparities in the United States. Volume 51, Issue 5, pp 1597-1618.

Mann M. (1986) Gender and Stratification: Towards a New Approach. Polity Press, Cambridge. Pp. 23-39.

Marshall, A. (1995). Regímenes institucionales de determinación salarial y estructura de los salarios, Argentina (1976-1993), Desarrollo económico. Vol. 35, No. 138. Julio-septiembre. pp. 275-288.

Marshall, A. (1999). Wage determination regimes and pay inequality: A comparative study of Latin American countries, International Review of Applied Economics, Vol. 13, No.1. enero.

Marshall, A. (2002), Transformaciones en el empleo y la intervención sindical en la industria: efectos sobre la desigualdad de salarios, Desarrollo económico. Vol.42. No. 166. Julio-septiembre. pp. 211230

Martínez-Jasso, Irma y Gloria Acevedo-Flores (2004), "La brecha salarial en México con enfoque de género: Capital humano, discriminación y selección muestral", Ciencia, 7(1), Universidad Autónoma de Nuevo León, Monterrey, pp.66-71.

Melly Blaise. 2005. Descomposition of diferences indistribution using quiantile regression. Labour Economic. 12(4): 577-590.

Mendoza Eduardo y García Karina. (2009). "Discriminación salarial por género en México", Problemas del Desarrollo, Instituto de Investigaciones Económicas, UNAM, Vol. 40, Núm. 156, enero-marzo 2009, pp.77-99.

Menon y Van Der M. Rodgers (2009) "International Trade and the Gender Wage Gap: New Evidence from India's Manufacturing Sector”, World Development, Vol.37. pp. 965-81.

Mincer, J. (1962). Labor force participation of married women, Aspects of Labor Economics. NBER, Princeton University Press.

Neumark, D., 1988, "Employers' Discriminatory Behavior and the Estimation of Wage Discrimination", The Journal of Human Resources, 23(3), 279-295.

Nopo, Hugo, Nancy, Daza and Johanna Ramos. 2011. Gender earnings gaps in the world. Institute for the study of labor (IZA). Num. 5736. 
O'Neill, Blau and Kahn (1996) Women's Work and Wages. Cornell University and Princeton University. Journal of Labor Economics 11, 205-228.

Oaxaca R. y Ramson M. (1994), "On discrimination and the decomposition of wage differentials", Journal of Econometric, Vol. 61, Pp. 279-295.

Oaxaca Ronald (1973), "Male-female wage differentials in urban labour markets", International Economic Review. 14 (3), University of Pennsylvania-The Osaka University Philadelphia. Pp. 693709 .

Oaxaca, R. y Ransom, M. (1999). Identification in Detailed Wage Decompositions, The Review of Economics and Statistics. Vol. 81, No. 1. Febrero. Pp.154-157.

Olivetti C \& Petrolongo B. (2008) Unequal Pay or Unequal Employment? A CrossCountry Analysis of Gender Gaps. Journal of Labor Economics, No. 26, pages 621-654. Boston University, United States.

Papadópulos, J. y Radakovich, R. (2006). Capítulo 8. Educación superior y género en América Latina y el Caribe en IESALC-UNESCO. Informe sobre la Educación Superior en América Latina y el Caribe 2000-2005. La metamorfosis de la Educación Superior. Instituto Internacional de la UNESCO para la Educación Superior en América Latina y el Caribe (IESALC). Venezuela. pp.117128

Phelps, E. (1972). The statistical theory of racism and sexism. American Economic Review. Vol. 14. Num. 3: 139-148.

Popli Gurleen (2013), "Gender wage differentials in México: A distributional approach"; Journal of the Royal Statistical Society: A. Vol. 176 (2), Statics in Society, London, Pp. 295-319.

Ramos, Vicente; Rey-Maquieira, Javier y Turgores, Maria. (2002) Analisis empírico de la discriminación por razón de género en una economía especializada en el turismo. Universitat de les Illes Balears, España. Vol. 4. Num. 1:239-258.

Robbins, D. (1994). Earnings dispersion in Chile after trade liberalization, Harvard University. Mimeo.

Rodríguez Pérez Reyna E. (2018). Brecha salarial por género en México: Desde un enfoque regional, según su exposición a la apertura comercial 2005-2015. Noesis. Revista de Ciencias Sociales y Humanidades. Número 54. Vol. 27. Julio-diciembre

Rodríguez Pérez Reyna E y David Castro Lugo (2014a). "Discriminación salarial de la mujer en el mercado laboral de México y sus regiones". Economía Sociedad y Territorio. Vol. XIV. Núm. 46. 655686.

Rodríguez Pérez Reyna E y David Castro Lugo. (2014b) “Análisis de la discriminación salarial por género en Saltillo y Hermosillo: un estudio comparativo en la industria manufacturera. Nóesis. Vol. 23. Núm. 46. 80-113.

Rodríguez Reyna Elizabeth y Mario Camberos Castro (2007). "Análisis de la discriminación de la mujer en Hermosillo, Sonora”, Revista Política y Cultura, Núm. 28. Universidad Autónoma Metropolitana- Xochimilco, pp. 225-256.

Rotter J. B. (1966) Generalized Expectancies For Internal Versus External Control of Reinforcement. Psychological Monographs, 80, pp. 1-28.

Rubery J. (1993) Gender Inequalities in Regional Development Pay: Gender and the Social Dimension to Europe, Oxford University Pres. Ind. Rel. 30, pp.605-21. 
Sánchez, M. y Lavié, J. (2011). El liderazgo y la asunción de cargos académicos en función del género en Marina Tomás (coord.). La universidad vista desde la perspectiva de género. Estudios sobre el profesorado. Editorial Octaedro. Colección Universidad. Barcelona. pp. 15-42.

Semykina, Anastasia and Susan, Linz. 2010. Analyzing the gender pay gap in transition economies: how much does personality matter? Human relations 63. Num.4. pp. 447-469.

Silva, P. (2004). El género en la sociedad en Chávez, J. (coord.). Perspectiva de género. Número uno. Serie Género y trabajo social. Escuela Nacional de Trabajo Social. Universidad Nacional Autónoma de México y Plaza y Valdés. México, pp. 13-22.

Sylos-Labini, P. (1974), Trade Unions. Inflation and Productivity, Saxon-House-Lexington Books.

Tenjo, J., Ribero, R. y Bernat, L. (2005). Evolución de las diferencias salariales por sexo en seis países de América Latina un intento de interpretación. Documento CEDE. 2005-18. Edición electrónica. Marzo. 59 pp.

Thurow L. (1978) Generating Inequality: Mechanisms of Distribution in the US. Economy New York: Basic Books.

Tomei, M. (2006). CAPÍTULO II. El nexo entre discriminación e igualdad de género en el trabajo: algunas consideraciones conceptuales y de políticas en Laís Abramo (editora). Trabajo decente y equidad de género en América Latina. Oficina Internacional del Trabajo. Organización Internacional del Trabajo. Santiago, Chile. pp.63- 94

Ullibarri, A (2003). Diferencias salariales entre los sectores públicos y privados por género, escolaridad y edad. El caso de España. El trimestre económico. Fondo de Cultura Económica, México. Vol. LXX (2). Num. 278: 233-253.

Valdivia, M. y Pedrero, M. (2011). Segmentación laboral, educación y desigualdad salarial en México, Revista mexicana de Sociología. Vol. 73, No. 1, Enero-marzo. Universidad Nacional Autónoma de México. pp. 139-175.

Wainerman (1996) La División Sexual del Trabajo en los Libros de Lectura de la Escuela Primaria Argentina: El Caso de Inmutabilidad Secular. Centro de Estudios de Población, Buenos Aires, Argentina. 